ARTICLE

Received 14 Sep 2015 | Accepted 29 Sep 2015 | Published 26 Oct 2015

DOl: $10.1038 /$ ncomms 9769

OPEN

\title{
Simultaneous enhancements in photon absorption and charge transport of bismuth vanadate photoanodes for solar water splitting
}

Tae Woo Kim ${ }^{1}$ Yuan Ping ${ }^{2, \dagger}$, Giulia A. Galli ${ }^{3}$ \& Kyoung-Shin Choi ${ }^{1}$

$\mathrm{n}$-Type bismuth vanadate has been identified as one of the most promising photoanodes for use in a water-splitting photoelectrochemical cell. The major limitation of $\mathrm{BiVO}_{4}$ is its relatively wide bandgap $(\sim 2.5 \mathrm{eV})$, which fundamentally limits its solar-to-hydrogen conversion efficiency. Here we show that annealing nanoporous bismuth vanadate electrodes at $350^{\circ} \mathrm{C}$ under nitrogen flow can result in nitrogen doping and generation of oxygen vacancies. This gentle nitrogen treatment not only effectively reduces the bandgap by $\sim 0.2 \mathrm{eV}$ but also increases the majority carrier density and mobility, enhancing electron-hole separation. The effect of nitrogen incorporation and oxygen vacancies on the electronic band structure and charge transport of bismuth vanadate are systematically elucidated by $a b$ initio calculations. Owing to simultaneous enhancements in photon absorption and charge transport, the applied bias photon-to-current efficiency of nitrogen-treated $\mathrm{BiVO}_{4}$ for solar water splitting exceeds $2 \%$, a record for a single oxide photon absorber, to the best of our knowledge.

\footnotetext{
${ }^{1}$ Department of Chemistry, University of Wisconsin-Madison, Madison, Wisconsin 53706, USA. ${ }^{2}$ Department of Chemistry, University of California, Davis, California 95616, USA. ${ }^{3}$ Institute for Molecular Engineering, University of Chicago, Chicago, Illinois 60637, USA. † Present address: Joint Center for Artificial Photosynthesis, Lawrence Berkeley National Laboratory, Berkeley, California 94720, USA; California Institute of Technology, Pasadena, California 91125, USA. Correspondence and requests for materials should be addressed to G.A.G. (email: gagalli@uchicago.edu) or to K.-S.C. (email: kschoi@chem.wisc.edu).
} 
T he major challenge for solar hydrogen production is the reduction of hydrogen production cost comparable to that of fossil-based fuels ${ }^{1-3}$. To make solar hydrogen production a reality, a significant cost reduction for the construction of a photoelectrochemical cell (PEC) is critical ${ }^{1-4}$. Among various semiconductor electrodes (photoelectrodes) for use in PECs, oxide-based photoelectrodes have the possibility of significantly lowering the materials and processing costs while being stable in aqueous media ${ }^{5-7}$. n-Type bismuth vanadate $\left(\mathrm{BiVO}_{4}\right)$ has recently emerged as one of the most promising photoanodes for use in water-splitting $\mathrm{PECs}^{8-11}$. It absorbs a substantial portion of the visible spectrum (bandgap energy, $\sim 2.5 \mathrm{eV}$ ) and has a favourable conduction band edge position, which is very near the thermodynamic $\mathrm{H}_{2}$ evolution potential ${ }^{8,9}$. As a result, it demonstrated the most negative photocurrent onset potential for water oxidation among all n-type semiconductors (photoanodes) having bandgaps in the visible region. Also, it appears to be fairly stable against chemical and photoelectrochemical corrosion ${ }^{9-11}$. A recent report shows that photoanodes composed of only oxide components, nanoporous $\mathrm{BiVO}_{4}$ electrodes coupled with $\mathrm{FeOOH}$ and $\mathrm{NiOOH}$ as oxygen evolution catalysts ${ }^{11}$, can achieve an applied bias photon-tocurrent efficiency (ABPE) for water splitting as high as $1.7 \%$ in a stable manner (equation for ABPE is shown in Supplementary Information) ${ }^{12}$. This result demonstrated the possibility for constructing a PEC for water splitting using only inexpensive and easy-to-process oxide components.

One of the major limitations of $\mathrm{BiVO}_{4}$ for further improving the solar energy conversion efficiency is its bandgap $(\sim 2.5 \mathrm{eV})$, which fundamentally limits photon absorption. Considering that there are a substantial number of photons in the $2.0-2.5 \mathrm{eV}$ region of the solar spectrum, a reduction in bandgap by even $0.1-0.3 \mathrm{eV}$ can result in a significant efficiency increase ${ }^{13,14}$. For example, if a bandgap is reduced from 2.5 to $2.3 \mathrm{eV}$, the maximum photocurrent $\left(J_{\max }\right)$ will increase from 6.47 to $9.12 \mathrm{~mA} \mathrm{~cm}^{-2}$ assuming $100 \%$ incident photon-to-current conversion efficiency (IPCE) for the photons that enable bandgap transition ${ }^{13}$. However, most previous doping studies of $\mathrm{BiVO}_{4}$ were to increase carrier densities ${ }^{15-18}$. Studies reporting the change in photon absorption of $\mathrm{BiVO}_{4}$ have been scarce and no clear elucidation of the effect of the dopants on the electronic band structures has been reported ${ }^{19,20}$. Considering that the valence band maximum (VBM) of $\mathrm{BiVO}_{4}$ is significantly more positive than water oxidation potential, but the conduction band minimum (CBM) of $\mathrm{BiVO}_{4}$ is very close to the reduction potential of water ${ }^{8,9,21}$, the reduction in bandgap of $\mathrm{BiVO}_{4}$ will be the most advantageous if it is achieved by raising the VBM.

In this study, we report that mild annealing treatment of nanoporous $\mathrm{BiVO}_{4}$ under $\mathrm{N}_{2}$ flow results in nitrogen incorporation into the oxygen sites, which effectively decreases the bandgap while also improving carrier mobility. In addition, we discover that the same $\mathrm{N}_{2}$ treatment generates oxygen vacancies that can increase the majority carrier density. The effect of nitrogen incorporation and oxygen vacancies on the electronic band structure and charge transport of $\mathrm{BiVO}_{4}$ are systematically elucidated by $a b$ initio calculations, which corroborate well with the experimental results. Owing to concurrent enhancement in photon absorption, carrier density and carrier mobility, the $\mathrm{N}_{2}$-treated $\mathrm{BiVO}_{4}$ electrode, when paired with oxygen evolution catalysts, breaks the wall of $2 \% \mathrm{ABPE}$ for solar water splitting, a first for a single oxide photoelectrode.

\section{Results}

Synthesis and characterization. Nanoporous $\mathrm{BiVO}_{4}$ electrodes were first prepared by the method described in a recent study, which involves electrochemical deposition of BiOI followed by thermal and chemical conversion to $\mathrm{BiVO}_{4}$ (ref. 11). Nitrogen doping of $\mathrm{BiVO}_{4}$ was achieved by annealing the $\mathrm{BiVO}_{4}$ electrodes at $350^{\circ} \mathrm{C}$ for $2 \mathrm{~h}$ while flowing $\mathrm{N}_{2}$. This is an exceptionally gentle procedure for nitrogen doping considering that nitridation or nitrogen doping of oxides is generally achieved by annealing with a flow of $\mathrm{NH}_{3}$ at much higher temperatures $\left(\geq 500^{\circ} \mathrm{C}\right)^{22-25}$. Annealing under $\mathrm{N}_{2}$ flow may create oxygen deficiencies in oxide compounds but is usually considered insufficient for nitrogen doping. We believe that the nanoparticulate nature of the $\mathrm{BiVO}_{4}$ electrodes played a role in enabling nitrogen doping under such mild conditions.

The scanning electron microscopy images and X-ray diffraction studies of $\mathrm{N}_{2}$-treated $\mathrm{BiVO}_{4}$ electrodes do not show noticeable changes from those of untreated $\mathrm{BiVO}_{4}$ (Fig. 1a-d; Supplementary Fig. 1). The first indication of nitridation was observed when a drop of water was placed on the surface of these electrodes to compare their hydrophilicities (Fig. 1e,f). While the $\mathrm{BiVO}_{4}$ sample showed a high affinity to water, as any oxide surface would, the $\mathrm{N}_{2}$-treated sample showed strong hydrophobicity, suggesting the possibility of nitridation, which can considerably change the hydrophilicity of the surface.

The incorporation of nitrogen into the $\mathrm{BiVO}_{4}$ lattice was confirmed by electron probe microanalyzer (EPMA) and X-ray photoelectron spectroscopy (XPS). For charge-balanced incorporation of nitrogen, three $\mathrm{O}^{2-}$ ions need to be removed for every two $\mathrm{N}^{3-}$ ions, creating one oxygen vacancy. Therefore, the formula of nitrogen-doped $\mathrm{BiVO}_{4}$ can be written as $\mathrm{BiVO}_{4-1.5 x} \mathrm{~N}_{x}$ if no other types of oxygen vacancies are present. The EPMA result showed that $x$ is $0.31 \pm 0.05$ (that is, $\mathrm{BiVO}_{3.54} \mathrm{~N}_{0.31}$ ). XPS study also confirmed the presence of nitrogen in the $\mathrm{BiVO}_{4}$ lattice by showing a $\mathrm{N} 1 s$ peak (Fig. 2a) with the nitrogen content, $x$, estimated to be $0.34 \pm 0.02$, which is comparable to the value obtained by EPMA. The location of the $\mathrm{N}$ 1s peak $(397-402 \mathrm{eV})$ agrees well with that of nitrogen incorporated into the oxide lattice ${ }^{25,26}$. The incorporation of $\mathrm{N}$ into the $\mathrm{BiVO}_{4}$ lattice was further confirmed by Raman spectra that show significant broadening of various $\mathrm{V}-\mathrm{O}$ stretching and
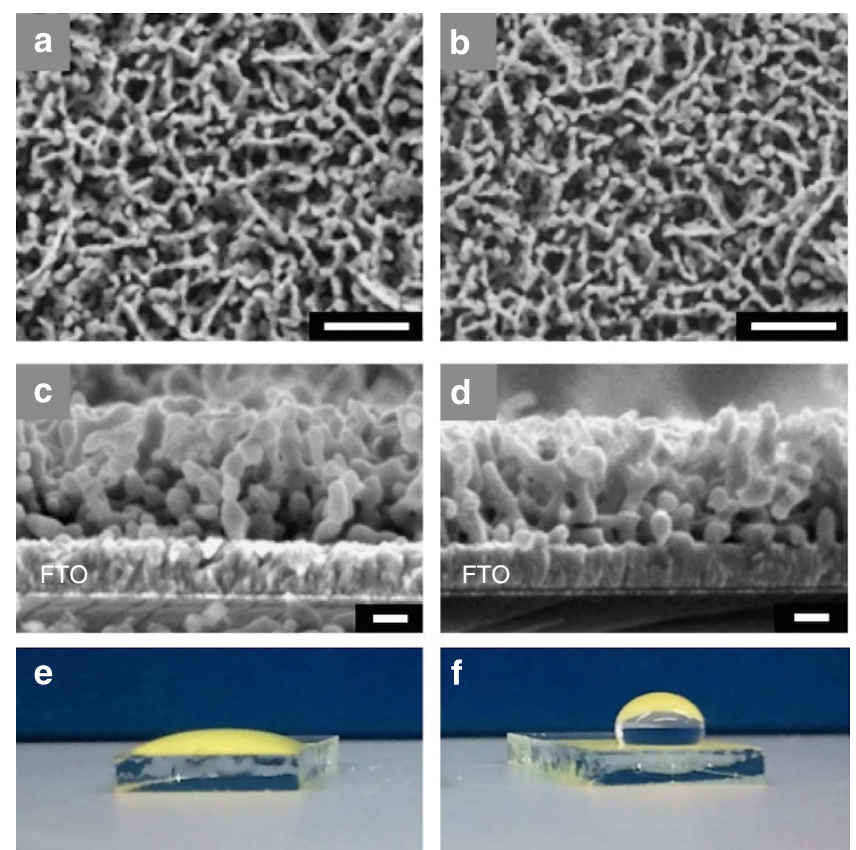

Figure 1 | SEM images and photographs. Top-view and side-view SEM images of $(\mathbf{a}, \mathbf{c}) \mathrm{BiVO}_{4}$ and $(\mathbf{b}, \mathbf{d}) \mathrm{N}_{2}$-treated $\mathrm{BiVO}_{4}$. Photographs of a water droplet placed on (e) $\mathrm{BiVO}_{4}$ electrode and (f) $\mathrm{N}_{2}$-treated $\mathrm{BiVO}_{4}$ electrode. Scale bars, $1 \mu \mathrm{m}$ for $(\mathbf{a}, \mathbf{b})$ and $200 \mathrm{~nm}$ for $(\mathbf{c}, \mathbf{d})$. 

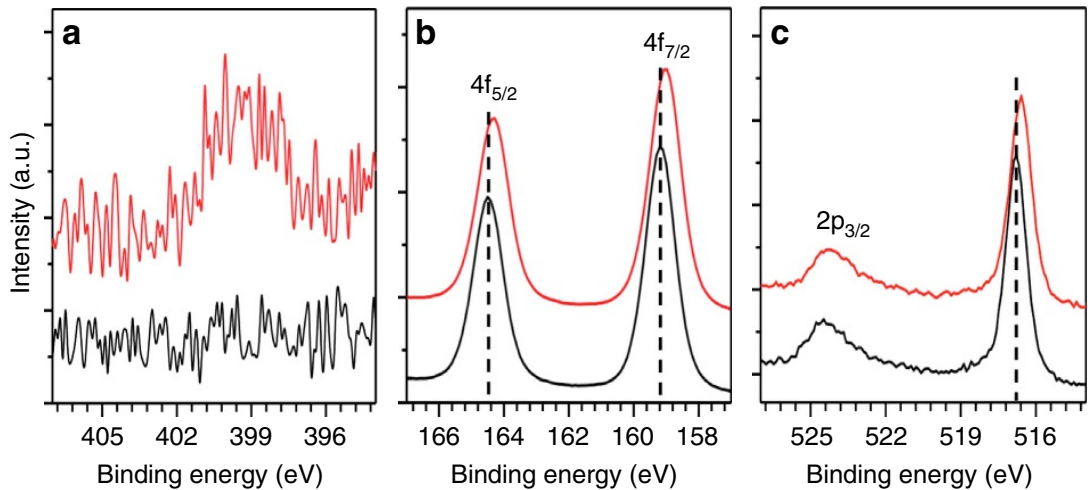

Figure 2 | XPS of $\mathbf{B i V O}_{\mathbf{4}}$ and $\mathbf{N}_{\mathbf{2}}$-treated BiVO $\mathbf{4}_{\mathbf{4}}$ (a) 1 s peaks of $\mathrm{N}_{1}(\mathbf{b}) 4 f$ peaks of $\mathrm{Bi}$ and (c) $2 p$ peaks of $\mathrm{V}$ for $\mathrm{BiVO}_{4}$ (black) and $\mathrm{N}_{2}$-treated $\mathrm{BiVO} \mathrm{O}_{4}$ (red).

$\mathrm{VO}_{4}^{3-}$ deformation modes of the bulk sample (Supplementary Fig. 2) 27,28 . This indicates that unlike other oxides, nitrogen incorporation into $\mathrm{BiVO}_{4}$ can occur using $\mathrm{N}_{2}$ as the $\mathrm{N}$ source at mild temperatures. In fact, there exist two previous studies reporting nitrogen incorporation into vanadium oxides by annealing under $\mathrm{N}_{2}$ flow ${ }^{29,30}$, suggesting relatively easy nitrogen incorporation into vanadium-based oxides.

The XPS study also revealed that the $\mathrm{Bi} 4 f$ and $\mathrm{V} 2 p$ peaks of $\mathrm{N}_{2}$-treated $\mathrm{BiVO}_{4}$ were shifted to the lower binding energy (Fig. 2b,c). This should be due to the changes in local coordination environments of $\mathrm{Bi}$ and $\mathrm{V}$ ions, including a change in ligand type ( $\mathrm{O}$ to $\mathrm{N}$ ) and a decrease in coordination number due to oxygen vacancies compensating the charge difference between $\mathrm{O}^{2-}$ and $\mathrm{N}^{3-}$. In addition, the possibility that the $\mathrm{N}_{2}$ treatment created additional oxygen vacancies ${ }^{31,32}$, which would result in partial reduction of $\mathrm{Bi}^{3+}$ and $\mathrm{V}^{5+}$ ions, cannot be excluded.

The ultraviolet-visible spectra of $\mathrm{BiVO}_{4}$ and $\mathrm{N}_{2}$-treated $\mathrm{BiVO}_{4}$ electrodes are shown in Fig. $3 \mathrm{a}$. The $\mathrm{N}_{2}$-treated sample clearly showed a shift of the bandgap absorption to lower energy compared with untreated $\mathrm{BiVO}_{4}$. This agrees well with the darker yellow colour of the $\mathrm{N}_{2}$-treated $\mathrm{BiVO}_{4}$ (Fig. 3a, inset). The $\mathrm{N}_{2}$-treated $\mathrm{BiVO}_{4}$ also shows a significant absorption before the absorption edge (wavelength $>550 \mathrm{~nm}$ ). This is most likely due to $\mathrm{N}_{2}$ treatment generating significant disorder in the atomic arrangement (for example, $\mathrm{O}$ defects) on the surface of the high surface area nanoporous $\mathrm{BiVO}_{4}$ electrode while incorporating nitrogen, creating interband states in the bandgap region ${ }^{33,34}$. The absorption due to these interband states makes it difficult to accurately assess the onset for the bandgap transition.

Photo-oxidation of sulfite. To determine the onset of photon absorption that contributes to the photocurrent generation, wavelength-dependent photocurrent was measured using monochromatic light for the photo-oxidation of sulfite and the IPCE was calculated. Since the oxidation kinetics of sulfite is fast, surface electron-hole recombination is negligible during photo-oxidation of sulfite. Therefore, photo-oxidation of sulfite enables a more precise estimation of photocurrent onset compared with photo-oxidation of water which typically suffers from slow oxidation kinetics and surface recombination.

The IPCE result obtained at $0.6 \mathrm{~V}$ versus reversible hydrogen electrode (RHE) shows that the photocurrent onset of the $\mathrm{N}_{2}$-treated sample lies between 540 and $550 \mathrm{~nm}(\sim 2.27 \mathrm{eV})$ while that of the untreated sample lies between 500 and $510 \mathrm{~nm}$ $(\sim 2.46 \mathrm{eV})$, which indicates a bandgap reduction of $\sim 0.2 \mathrm{eV}$ for the $\mathrm{N}_{2}$-treated sample (Fig. 3b). The $J-V$ plots of $\mathrm{BiVO}_{4}$ and $\mathrm{N}_{2}$-treated $\mathrm{BiVO}_{4}$ obtained using $\mathrm{AM}$ 1.5G illumination for sulfite oxidation are also shown in Fig. $3 c$. The $\mathrm{N}_{2}$-treated $\mathrm{BiVO}_{4}$ a
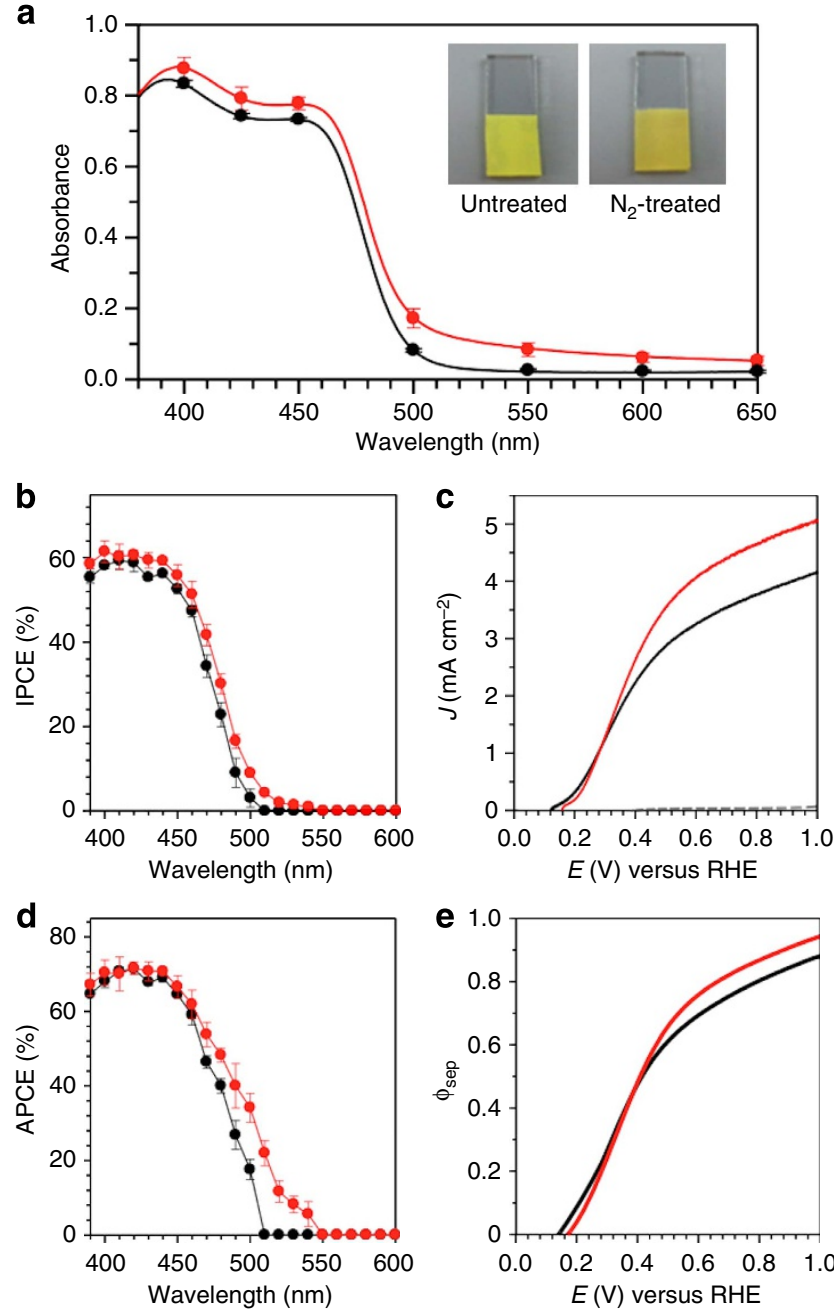

Figure 3 | Optical and photoelectrochemical properties. (a) Ultravioletvisible absorption spectra with photographs of samples, (b) IPCE at $0.6 \mathrm{~V}$ versus $R H E$, (c) J-V plots for sulfite oxidation under AM 1.5G, $100 \mathrm{~mW} \mathrm{~cm}^{-2}$ illumination (scan rate, $10 \mathrm{mVs}^{-1}$ ), (d) APCE at $0.6 \mathrm{~V}$ versus RHE and (e) $\phi_{\text {sep }} \mathrm{s}$ calculated from the $J-V$ plots for $\mathrm{BiVO}_{4}$ (black) and $\mathrm{N}_{2}$-treated $\mathrm{BiVO}_{4}$ (red). A $0.5 \mathrm{M}$ phosphate buffer ( $\mathrm{pH}$ 7.2) containing $1 \mathrm{M} \mathrm{Na}_{2} \mathrm{SO}_{3}$ was used as the electrolyte. The error bars were obtained by taking the s.d. values of measurements on three different samples.

electrode shows a significantly higher photocurrent than the $\mathrm{BiVO}_{4}$ electrode. For example, the $\mathrm{N}_{2}$-treated sample generated a photocurrent density of $4.16 \pm 0.41 \mathrm{~mA} \mathrm{~cm}^{-2}$ at $0.6 \mathrm{~V}$ versus RHE while $\mathrm{BiVO}_{4}$ generated $3.27 \pm 0.31 \mathrm{~mA} \mathrm{~cm}^{-2}$ at the same 
potential, corresponding to a $27 \%$ increase. This is the first example showing the generation of photocurrent higher than $4 \mathrm{~mA} \mathrm{~cm}^{-2}$ for any photo-oxidation reaction by any photoanode reported to date at a potential as low as $0.6 \mathrm{~V}$ versus RHE.

If the photocurrent enhancement is due only to the enhanced photon absorption by the bandgap reduction, the $\mathrm{N}_{2}$-treated sample should show an increase in IPCE but not in the absorbed photon-to-current conversion efficiency (APCE). However, the $\mathrm{N}_{2}$-treated sample showed a considerable enhancement in APCE, particularly between 470 and $550 \mathrm{~nm}$ (Fig. 3d), indicating that the $\mathrm{N}_{2}$ treatment also improved electron-hole separation. Indeed, the electron-hole separation yield, $\phi_{\text {sep}}$, of the $\mathrm{N}_{2}$-treated sample, which was calculated from the $J-V$ plots obtained for sulfite oxidation, shows about an $8-10 \%$ increase at $E>0.45 \mathrm{~V}$ versus RHE (Fig. 3e). For example, the electron-hole separation yields at $0.6 \mathrm{~V}$ versus RHE are $0.70 \pm 0.04$ and $0.76 \pm 0.07$ for untreated and $\mathrm{N}_{2}$-treated $\mathrm{BiVO}_{4}$, respectively. This means that the $27 \%$ photocurrent enhancement observed at $0.6 \mathrm{~V}$ for the $\mathrm{N}_{2}$-treated sample is partially due to an increase in photon absorption and partially due to an increase in electron-hole separation (see the Methods section and Supplementary Table 1 for detailed calculations).

One plausible mechanism for $\mathrm{N}_{2}$ treatment to increase $\phi_{\text {sep }}$ is to increase the carrier density by creating extra oxygen vacancies, which can serve as donors, in addition to the oxygen vacancies created for charge-balanced substitution of $\mathrm{N}^{3-}$ with $\mathrm{O}^{2-}$. This can result in an improvement in electron transport and, therefore, in electron-hole separation. The carrier densities in $\mathrm{BiVO}_{4}$ and $\mathrm{N}_{2}$-treated $\mathrm{BiVO}_{4}$ electrodes were compared by obtaining Mott-Schottky plots (Supplementary Fig. 3). For nanoporous films, since the regions that contribute to space-charge layer capacitance and the corresponding surface area cannot be precisely quantified, accurate quantitative analysis of carrier density using Mott-Schottky analysis is not possible. However, since the samples compared in this study have exactly the same morphologies (particle sizes, aggregations and connectivities), relative qualitative comparison of carrier densities should be possible by comparing the magnitude of the slopes. The result shows that the slope of $\mathrm{N}_{2}$-treated $\mathrm{BiVO}_{4}$ is $\sim 1 / 7$ of the slope of $\mathrm{BiVO}_{4}$, indicating that the $\mathrm{N}_{2}$-treated $\mathrm{BiVO}_{4}$ electrodes possess extra oxygen vacancies that serve as electron donors. This suggests that the record-high photocurrent shown in Fig. $3 \mathrm{c}$ is due to improved electron transport properties as well as bandgap reduction.

An increase in n-type carrier density should result in a shift of flatband potential $\left(E_{\mathrm{FB}}\right)$ to the negative direction. However, both the photocurrent onset and the $E_{\mathrm{FB}}$ of the $\mathrm{N}_{2}$-treated sample are more positive than those of $\mathrm{BiVO}_{4}$ (Fig. 3c; Supplementary Fig. 3). This is because the Helmholtz layer potential drop $\left(V_{\mathrm{H}}\right)$ of the $\mathrm{N}_{2}$-treated $\mathrm{BiVO}_{4}$ electrode, which is another factor that affects the position of $E_{\mathrm{FB}}$ (ref. 35), is more positive than that of $\mathrm{BiVO}_{4}$, which is indicated by zeta potential measurements (Supplementary Fig. 4). The change in $V_{\mathrm{H}}$ of the $\mathrm{N}_{2}$-treated sample appears to cancel out the effect of an increased donor density on $E_{\mathrm{FB}}$.

Density functional theory calculations. The effect of chargebalanced $\mathrm{N}$ incorporation (that is, replacing three $\mathrm{O}^{2-}$ with two $\mathrm{N}^{3-}$ ) and of oxygen vacancies on the electronic band structure of $\mathrm{BiVO}_{4}$ were studied using density functional theory (DFT) calculations, to gain insights into the changes occurring in $\mathrm{BiVO}_{4}$ upon nitridation. Our experimental results show that in the $\mathrm{N}_{2}$-treated $\mathrm{BiVO}_{4}$, both $\mathrm{N}$ substitution and $\mathrm{O}$ vacancies are present at the same time, yielding a complex, combined effect on the electronic structure of $\mathrm{BiVO}_{4}$. Before investigating such combined effect, we discuss the electronic properties of $\mathrm{N}$ substitution and oxygen vacancies separately.

We first performed spin-polarized calculations without addressing the charge imbalance between $\mathrm{O}^{2-}$ and $\mathrm{N}^{3-}$. We used the Perdew-Burke-Ernzerh (PBE) ${ }^{36}$ exchange correlation functional for pure $\mathrm{BiVO}_{4}$ and $\mathrm{BiVO}_{4}$ with $12.5 \%$ neutral $\mathrm{O}$ replaced with neutral $\mathrm{N}$ (1:1 substitution). We found that in the presence of $\mathrm{N}$ the bandgap of $\mathrm{BiVO}_{4}$ was reduced by $0.5 \mathrm{eV}$ (Supplementary Fig. 5), mainly because of the hybridization of $\mathrm{N}$ and $\mathrm{O} 2 p$ states close to VBM. The presence of extra holes due to $\mathrm{N}$ substitution leads to two localized empty bands (level labelled 'a' in Supplementary Fig. 5b) inside the bandgap of $\mathrm{BiVO}_{4}$. These bands will no longer be present when $\mathrm{N}$ substitution accompanies charge-balancing $\mathrm{O}$ vacancies, which will serve as electron donors and compensate for excess holes from $\mathrm{N}$ substitution, as discussed below (see also Supplementary Fig. 6 for the effect of artificially adding an electron per nitrogen to compensate for the excess holes from $\mathrm{N}$ substitution).

To understand the effect of $\mathrm{O}$ vacancies separately, we performed spin-polarized calculations at two different vacancy concentrations of 6 and 1.5\%, using PBE and PBE with Hubbard $U$-corrections ${ }^{37}(\mathrm{PBE}+U \text {, effective } U(\mathrm{~V})=2.7 \mathrm{eV})^{17}$, to verify the robustness of our results with respect to the functional adopted in our calculations. Both at the PBE and PBE $+U$ levels of theory, at the two concentrations, we found that the presence of $\mathrm{O}$ vacancies, which were created by removing neutral $\mathrm{O}$ atoms, did not lead to any modification of the bandgap of $\mathrm{BiVO}_{4}$ (for details see Supplementary Figs 7 and 8). We also observed the formation of localized, filled states inside the bandgap of pristine $\mathrm{BiVO}_{4}$. Interestingly, the spin density of the gap states is localized on $\mathrm{V}$, as shown in Supplementary Fig. 8, causing local lattice distortions (in addition to those induced by missing $\mathrm{O}$ atoms), and indicating the formation of small polarons. Indeed, small polarons are likely to form in oxides such as $\mathrm{BiVO}_{4}$ that exhibit strong electron-phonon interaction, as indicated, for example, by the large difference between the high frequency and static dielectric constants $\varepsilon$ (the high frequency and static $\varepsilon$, averaged over the three lattice directions, are 6.9 and 52, respectively, as computed by density functional perturbation theory ${ }^{38}$ for pure $\mathrm{BiVO}_{4}$ ).

Our results on the formation of small polarons are consistent with recent mobility measurements on single crystal $n$-type $\mathrm{BiVO}_{4}$, which reported very low electron mobilities ${ }^{39}$ $\left(\sim 0.2 \mathrm{~cm}^{-2} \mathrm{~V}^{-2} \mathrm{~s}^{-1}\right)$ and suggested that the conduction of electrons is dominated by small polaron hopping. Previous calculations showed that $\mathrm{O}$ vacancies lead to shallow donor levels in $\mathrm{BiVO}_{4}$ (ref. 31), with negative ionization energies for $E\left(\mathrm{~V}^{0} / \mathrm{V}^{2+}\right)$ and that the only stable charged state for an $\mathrm{O}$ vacancy in $\mathrm{BiVO}_{4}$ is $q=+2$ due to the spontaneous ionization of two electrons, regardless of the Fermi level position ${ }^{40}$. These results are consistent with our finding that the two electrons present at an $\mathrm{O}$ vacancy site are ionized and localized at $\mathrm{V}$ atoms, thus forming small polarons. Similar findings for $\mathrm{SrTiO}_{3}$ have also been discussed in a recent study by Janotti et al. ${ }^{41} \mathrm{We}$ also computed the small polaron binding energy ${ }^{42}$, that is, the energy difference between bound small polarons and free carriers. We found a non-negligible value of $\sim 0.50 \mathrm{eV}$ indicating that the formation of small polarons is energetically favourable (see Methods for calculation details).

Having established the separate effects of $\mathrm{N}$ substitution and $\mathrm{O}$ vacancies on the electronic structure of $\mathrm{BiVO}_{4}$, we now turn to analyze their combined effect. In the case of charge-balanced $\mathrm{N}$ substitution ( $9 \% \mathrm{O}$ replaced with $6 \% \mathrm{~N}$ and $3 \% \mathrm{O}$ vacancy) we found that no states are formed in the bandgap of $\mathrm{BiVO}_{4}$, as shown in Fig. 4a. This is because the electrons ionized from $\mathrm{O}$ vacancies compensate for the holes generated by $\mathrm{N}$ substitution, 

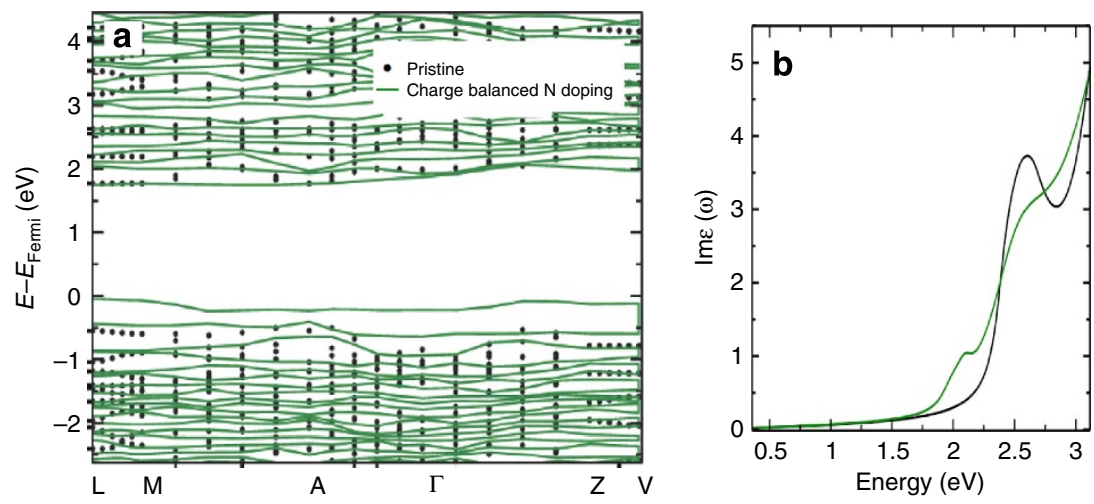

Figure 4 | Comparison of pristine and charge-balanced $\mathbf{N}$-doped $\mathbf{B i V O}_{\mathbf{4}}$ (a) Band structures and (b) simulated absorption spectra (imaginary part of dielectric function) of pristine $\mathrm{BiVO}_{4}$ (black) and $\mathrm{BiVO}_{4}$ with charge-balanced $\mathrm{N}$-doping ( $9 \% \mathrm{O}$ replaced with $6 \% \mathrm{~N}$ and $3 \% \mathrm{O}$ vacancy) (green). An artificial broadening $0.08 \mathrm{eV}$ is applied to take into account the finite temperature and phonon effects. The highest occupied level at $0 \mathrm{~K}$ of $\mathrm{BiVO}_{4}$ with charge-balanced $\mathrm{N}$-doping was taken as the Fermi level $\left(E_{\mathrm{Fermi}}\right)$.

thus balancing the charge. No small polaron is formed at the vanadium sites in this case. The important finding is that the bandgap is still lowered by $0.3-0.4 \mathrm{eV}$ (depending on the location in the lattice of the substituted $\mathrm{N}$ ) compared to that of pure $\mathrm{BiVO}_{4}$. The computed projected density of states (as shown in Supplementary Fig. 9) showed that the VBM has contributions from both $\mathrm{O}$ and $\mathrm{N} 2 \mathrm{p}$ states, similar to the case of $\mathrm{N}$ substitution discussed earlier. With lower doping concentration $(4.5 \% \mathrm{O}$ replaced with $3 \% \mathrm{~N}$ and $1.5 \% \mathrm{O}$ vacancy), the VBM moves upward by $0.2 \mathrm{eV}$ compared with that of pure $\mathrm{BiVO}_{4}$. In sum, we found that in the presence of $\mathrm{N}$ substitution and chargecompensating $\mathrm{O}$ vacancies, the bandgap decrease is similar to that obtained in the case where only substitutional $\mathrm{N}$ is present, and the bandgap decrease is more pronounced with increasing $\mathrm{N}$ concentration.

The information on energy levels provided by band structure calculations is insufficient to investigate light absorption efficiency of $\mathrm{BiVO}_{4}$. Hence, we also computed the optical transition probabilities from valence to conduction states for pristine and charge-balanced $\mathrm{N}$-doped $\mathrm{BiVO}_{4}(9 \% \mathrm{O}$ replaced with $6 \% \mathrm{~N}$ and $3 \% \mathrm{O}$ vacancy) and simulated absorption spectra using the random phase approximation including local field effects ${ }^{43}$. Although this approximation neglects excitonic effects, we expect it to be accurate to account for changes in absorption spectra when $\mathrm{N}$ is added to the sample ${ }^{44}$. We estimated the change of the exciton binding energy before and after doping by using a hydrogen-like model and we found it is of the order of $0.05 \mathrm{eV}$ (see Methods for details). The spectra were averaged over three lattice directions to compare with experimental results obtained from polycrystalline samples. The resulting simulated absorption spectra show that the absorption edge of $\mathrm{N}$-doped $\mathrm{BiVO}_{4}$ is lower than that of the pristine $\mathrm{BiVO}_{4}$ by about $0.3 \mathrm{eV}$ (Fig. 4b), confirming that charge-balanced $\mathrm{N}$ substitution can indeed enhance visible light absorption at lower energy. This result agrees well with our experimental observation that incorporating $\sim 8 \% \mathrm{~N}$ results in a $0.2 \mathrm{eV}$ reduction of the bandgap.

Our experimental results suggest that in addition to the $\mathrm{O}$ vacancies caused by charge-balanced replacement of $\mathrm{O}^{2-}$ with $\mathrm{N}^{3-}$, additional oxygen vacancies are present serving as electron donors in $\mathrm{N}_{2}$-treated $\mathrm{BiVO}_{4}$. Therefore, we performed calculations of $\mathrm{N}$-doped $\mathrm{BiVO}_{4}$ with excess $\mathrm{O}$ vacancies $(6 \% \mathrm{~N}$ and $6 \%$ $\mathrm{O}$ vacancy) (Fig. 5; Supplementary Fig. 10), where half of the $\mathrm{O}$ vacancies balance the charges of substitutional $\mathrm{N}$ atoms, and the other half provide extra electrons to form polarons. We observed both a reduction of the bandgap by $0.3 \mathrm{eV}$ (Fig. 5a), compared with that of pristine $\mathrm{BiVO}_{4}$, and the formation of small polarons localized on $\mathrm{V}$ atoms (Fig. 5b).

We also note that $\mathrm{N}$-doping increases the mobility of small polarons by changing the static dielectric constant of $\mathrm{BiVO}_{4}$ (ref. 45). Our computation shows that small polarons' activation energy of $\mathrm{N}$-doped $\mathrm{BiVO}_{4}(6 \% \mathrm{~N}$ substitution and 3\% $\mathrm{O}$ vacancies) is lowered by $1.1 \%$ and, as a result, the electron mobility is increased by $25 \%$ according to the small polaron model (see the Methods section for the computation details) ${ }^{39,42}$. This means that the measured, enhanced $\phi_{\text {sep }}$ of the $\mathrm{N}_{2}$-treated sample is not only due to an increase in carrier density but also due to an increase in carrier mobility. To confirm this, we prepared $\mathrm{H}_{2}$-treated $\mathrm{BiVO}_{4}$ that has the same $\mathrm{O}$ vacancy concentration and, therefore, the same carrier density as the $\mathrm{N}_{2}$-treated sample but no $\mathrm{N}$ incorporation (Supplementary Fig. 11) $)^{31}$. By comparing electron transport properties of the two samples using APCEs and photocurrents generated by frontside and back-side illuminations (Supplementary Figs 11 and $12)^{16,46-48}$, we observed that the electron transport of $\mathrm{N}_{2}$-treated samples is more enhanced than that of $\mathrm{H}_{2}$-treated samples. This result suggests that other than the carrier density increase by $\mathrm{O}$ vacancies that are common for $\mathrm{H}_{2}$-treated and $\mathrm{N}_{2}$-treated samples, the $\mathrm{N}_{2}$-treated samples have an additional factor improving electron transport. This agrees well with the result from the polaron activation energy calculation that $\mathrm{N}$ incorporation results in an increase in polaron mobility.

Altogether, our experimental and computational results show that the simple and mild $\mathrm{N}_{2}$ treatment used in this study simultaneously enhanced photon absorption, carrier density and carrier mobility, all of which are critical for improving the photoelectrochemical properties of $\mathrm{BiVO}_{4}$.

Photo-oxidation of water. The ability of $\mathrm{N}_{2}$-treated $\mathrm{BiVO}_{4}$ electrode to photoelectrolyze water was examined in a $0.5 \mathrm{M}$ phosphate buffer ( $\mathrm{pH}$ 7.2) after oxygen evolution catalysts (OECs), $\mathrm{FeOOH}$ and $\mathrm{NiOOH}$, were photodeposited on the $\mathrm{N}_{2}$-treated $\mathrm{BiVO}_{4}$ surface sequentially; a FeOOH layer was first photodeposited on the $\mathrm{N}_{2}$-treated $\mathrm{BiVO}_{4}$ surface followed by the deposition of a NiOOH (see Methods for the synthesis details). It was reported that the $\mathrm{BiVO}_{4} / \mathrm{FeOOH}$ interface minimizes electron-hole recombination at the $\mathrm{BiVO}_{4} / \mathrm{FeOOH}$ junction and the $\mathrm{NiOOH} /$ electrolyte surface makes the surface charge more favourable while concurrently improving the water oxidation kinetics ${ }^{11}$. As a result, the dual catalyst layer structure provided the best performance compared with single layer or the OEC layers with the reversed order. 

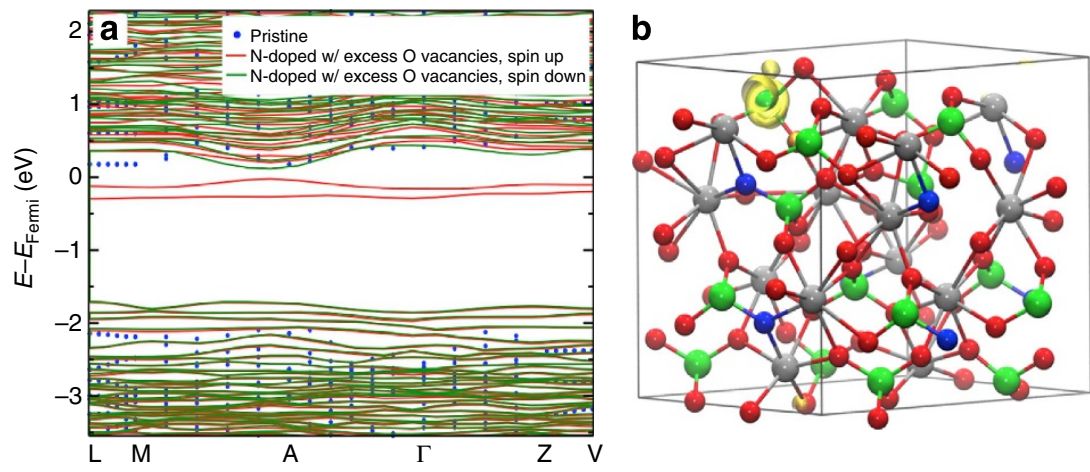

Figure 5 | Calculation results for $\mathbf{N}$-doped $\mathbf{B i V O}_{\mathbf{4}}$ with excess $\mathbf{O}$ vacancies. (a) Comparison of band structures of pristine $\mathrm{BiVO}_{4}(\mathrm{blue}$ dot) and $\mathrm{N}$-doped $\mathrm{BiVO}_{4}$ with excess $\mathrm{O}$ vacancies ( $6 \% \mathrm{~N}$ and $6 \% \mathrm{O}$ vacancy) with spin up (red) and spin down (green) configurations. The highest occupied level at $\mathrm{OK}$ of $\mathrm{N}$-doped $\mathrm{BiVO}_{4}$ with excess $\mathrm{O}$ vacancies (spin up configuration) was taken as the Fermi level ( $E_{\mathrm{Fermi}}$ ). (b) Spin density map of $\mathrm{N}$-doped $\mathrm{BiVO}{ }_{4}$ with excess $\mathrm{O}$ vacancies showing the localization of an electron on $\mathrm{V}$. The spin density isosurface $\left(0.0049 \mathrm{ebohr}^{-3}\right.$ ) of an isolated band (around the Fermi level at the $\Gamma$ point) is shown in yellow; atoms are represented by spheres: $\mathrm{V}$ (green), Bi (silver), $\mathrm{O}$ (red) and $\mathrm{N}$ (blue). Projected density of states is shown in Supplementary Fig. 10.

Since the surface of the $\mathrm{N}_{2}$-treated $\mathrm{BiVO}_{4}$ electrode is expected to be quite different from that of the untreated $\mathrm{BiVO}_{4}$ electrode (for example, surface charge and surface termination), the $\mathrm{N}_{2}$-treated $\mathrm{BiVO}_{4} / \mathrm{FeOOH}$ interface may no longer be ideal. However, depositing the same OECs on $\mathrm{BiVO}_{4}$ and $\mathrm{N}_{2}$-treated $\mathrm{BiVO}_{4}$ would allow us to examine any changes at the $\mathrm{BiVO}_{4} / \mathrm{OEC}$ junction and for solar water oxidation caused solely by $\mathrm{N}_{2}$ treatment.

The results show that $\mathrm{N}_{2}$ treatment increased the photocurrent density for water oxidation at $0.6 \mathrm{~V}$ versus RHE from 2.71 to $3.47 \mathrm{~mA} \mathrm{~cm}^{-2}$ (Fig. 6a). The $J-V$ curve was also measured using a two-electrode cell to calculate ABPE (Fig. 6b). The highest ABPE, $2.2 \%$, was achieved at $0.58 \mathrm{~V}$, which is the record-high $\mathrm{ABPE}$ attained by a single oxide photon absorber to date (Fig. 6c). The Faradaic efficiency for $\mathrm{O}_{2}$ evolution at $0.6 \mathrm{~V}$ versus $\mathrm{RHE}$ was $96 \%$ (Fig. 6d). The ratio of $\mathrm{H}_{2}: \mathrm{O}_{2}$ produced was 1.81:1 (Fig. 6d). Considering that there are no competing reactions available at the cathode, the slight deviation from the stoichiometric $\mathrm{H}_{2} / \mathrm{O}_{2}$ production is due to the leak of $\mathrm{H}_{2}$ during manual sampling of $\mathrm{H}_{2}$ for gas chromatography analysis.

The long-term stability of $\mathrm{N}_{2}$-treated $\mathrm{BiVO}_{4} / \mathrm{FeOOH} / \mathrm{NiOOH}$ for water oxidation was examined by measuring $J-t$ plots at $0.6 \mathrm{~V}$ versus RHE and was compared with the long-term stability of $\mathrm{N}_{2}$-treated $\mathrm{BiVO}_{4}$ for sulfite oxidation at the same potential (Fig. 6e). The photocurrent for sulfite oxidation was stable for $50 \mathrm{~h}$ and no sign of decay was observed, suggesting that the presence of nitrogen and oxygen vacancies in the lattice are stable under illumination and electrical bias. The photocurrent for water oxidation was stable for $30 \mathrm{~h}$ but after $30 \mathrm{~h}$ it gradually decreased. Considering the photostability of $\mathrm{N}_{2}$-treated $\mathrm{BiVO}_{4}$ for sulfite oxidation and the previously reported photostability of undoped $\mathrm{BiVO}_{4}$ combined with the same OECs for water oxidation ${ }^{11}$, the instability observed during photo-oxidation of water is most likely due to the instability of the $\mathrm{N}_{2}$-treated $\mathrm{BiVO}_{4} / \mathrm{OEC}$ junction resulting in the loss of OECs over time, which was confirmed by XPS studies (Supplementary Fig. 13). These results suggest that while $\mathrm{N}_{2}$-treated $\mathrm{BiVO}_{4}$ itself is compositionally stable, it will require new OECs to form a more stable $\mathrm{N}_{2}$-treated $\mathrm{BiVO}_{4} / \mathrm{OEC}$ interface to achieve a long-term stability for photo-oxidation of water.

\section{Discussion}

Annealing of nanoporous $\mathrm{BiVO}_{4}$ at $350^{\circ} \mathrm{C}$ under $\mathrm{N}_{2}$ flow resulted in substitutional incorporation of nitrogen and the formation of $\mathrm{O}$ vacancies, which simultaneously enhanced photon absorption, carrier density and carrier mobility. The effect of $\mathrm{N}$ incorporation and $\mathrm{O}$ vacancies in the $\mathrm{BiVO}_{4}$ lattice were thoroughly examined experimentally and computationally to provide new understanding of the electronic band structures and photoelectrochemical properties of $\mathrm{BiVO}_{4}$. Charge-balanced $\mathrm{N}$-doping (that is, $9 \% \mathrm{O}$ replaced with $6 \% \mathrm{~N}$ and $3 \% \mathrm{O}$ vacancy) reduced the bandgap of $\mathrm{BiVO}_{4}$ by elevating the VBM without introducing mid-gap states in the bandgap region. $\mathrm{N}$-doping also decreased the static dielectric constant of $\mathrm{BiVO}_{4}$ and improved the mobility of electrons, which are small polarons. In addition to the $\mathrm{O}$ vacancies required for charge-balanced $\mathrm{N}$-doping, the $\mathrm{N}_{2}$-treated $\mathrm{BiVO}_{4}$ contained additional oxygen vacancies, which served as electron donors in $\mathrm{N}_{2}$-treated $\mathrm{BiVO}_{4}$. As a result, the major carrier density as well as the major carrier mobility of $\mathrm{BiVO}_{4}$ could be increased by the simple $\mathrm{N}_{2}$ treatment. The experimental and theoretical studies reported herein may serve as guidelines to further improve photon absorption and charge transport of $\mathrm{BiVO}_{4}$-based photoanodes for more practical and efficient solar water splitting. For example, predicting and incorporating a dopant that can simultaneously improve photon absorption and charge transport may serve as an effective strategy to improve photoelectrochemical performance. Future studies should also include identifying OECs that can optimally interface with $\mathrm{BiVO}_{4}$ electrodes with modified compositions.

\section{Methods}

Nitrogen incorporation into $\mathbf{B i V O}_{4}$. The nanoporous $\mathrm{BiVO}_{4}$ electrode used in this study was prepared using the same method reported in our recent paper ${ }^{11,49}$ Nitrogen incorporation was achieved by annealing the $\mathrm{BiVO}_{4}$ electrodes at $350^{\circ} \mathrm{C}$ for $2 \mathrm{~h}$ in a tube furnace while flowing $\mathrm{N}_{2}$. This annealing condition was identified as optimal to generate samples with the best photoelectrochemical properties after trying various annealing temperatures $\left(300-450{ }^{\circ} \mathrm{C}\right.$, ramping rate $=5{ }^{\circ} \mathrm{C} \mathrm{min}^{-1}$ ) and annealing times $(1-3 \mathrm{~h})$. The $\mathrm{N}$ incorporation shown in this study is the maximum $\mathrm{N}$ incorporation that can be achieved by $\mathrm{N}_{2}$ treatment. Increasing temperature or duration of $\mathrm{N}_{2}$ treatment did not increase the $\mathrm{N}$ incorporation. When the duration of $\mathrm{N}_{2}$ treatment is shortened, the amount of $\mathrm{N}$ incorporated could be reduced but the photocurrent enhancement was also reduced. For example, when the annealing time at $350^{\circ} \mathrm{C}$ while flowing $\mathrm{N}_{2}$ was reduced from $2 \mathrm{~h}$ to $30 \mathrm{~min}$, the $\mathrm{N}$ content, $x$, in $\mathrm{BiVO}_{4-1.5 x} \mathrm{~N}_{x}$ was reduced from $=0.33$ to 0.10 judging from the XPS results and the photocurrent density at $0.6 \mathrm{~V}$ versus RHE was reduced from 4.2 to $3.4 \mathrm{~mA} \mathrm{~cm}^{-2}$.

Photodeposition of FeOOH/NiOOH OECs on $\mathbf{N}_{2}$-treated $\mathrm{BiVO}_{4}$ electrodes. The photodeposition of dual-layer oxygen evolution reaction catalysts (that is, $\mathrm{FeOOH}$ and $\mathrm{NiOOH}$ ) on the surface of the $\mathrm{N}_{2}$-treated $\mathrm{BiVO}_{4}$ photoanode were performed using the method described in our recent paper ${ }^{11}$ with a few modifications. Before photodeposition, the $\mathrm{N}_{2}$-treated $\mathrm{BiVO}_{4}$ was first immersed in $1 \mathrm{M} \mathrm{NaOH}$ solution for $\sim 1-2$ min to ensure the wetting of its hydrophobic surface. After rinsing the surface with DI water, the photodeposition of $\mathrm{FeOOH}$ was carried 
a
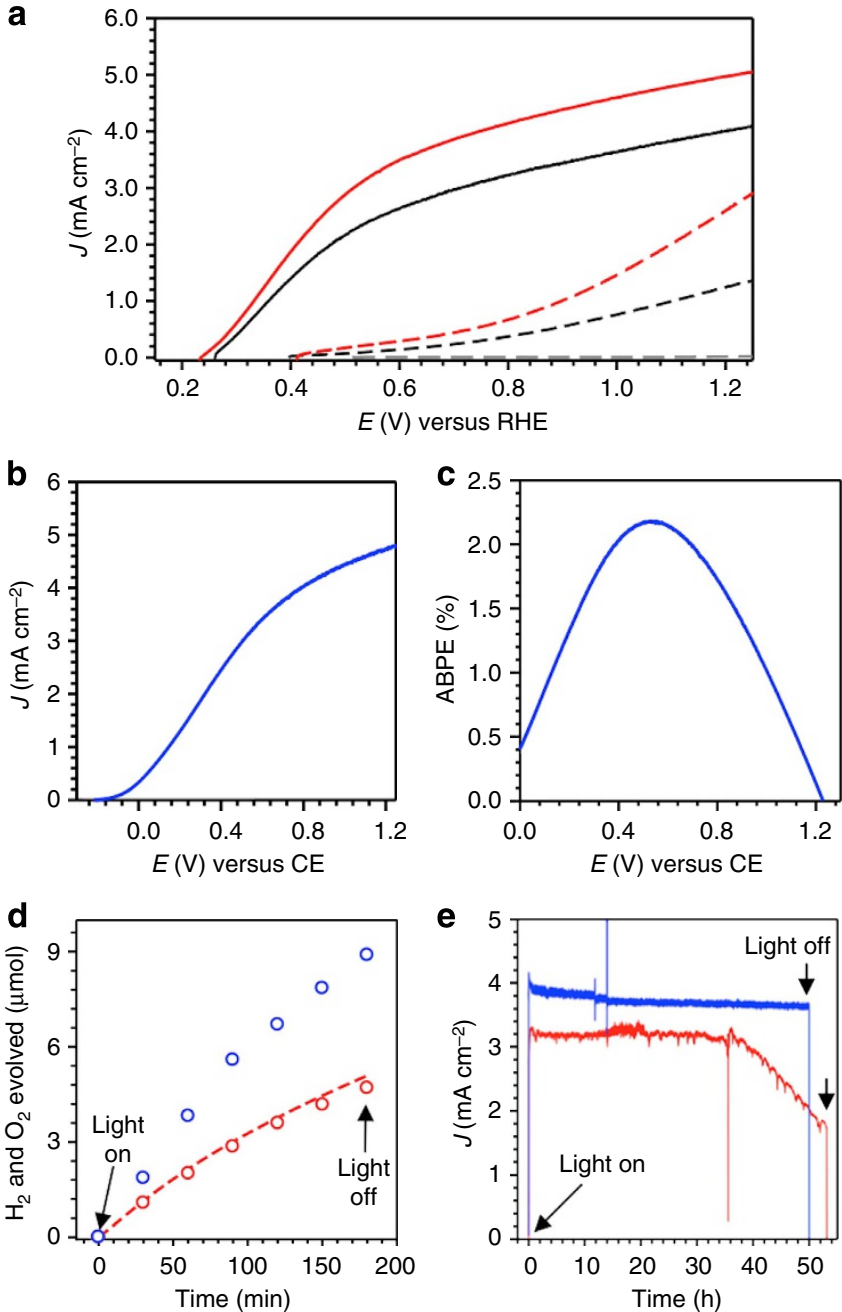

Figure 6 | Photoelectrochemical water-splitting performance.

(a) $J-V$ plots of $\mathrm{BiVO}_{4} / \mathrm{FeOOH} / \mathrm{NiOOH}$ (black, solid), $\mathrm{N}_{2}$-treated

$\mathrm{BiVO}_{4} / \mathrm{FeOOH} / \mathrm{NiOOH}$ (red, solid), $\mathrm{BiVO}_{4}$ (black, dashed), and $\mathrm{N}_{2}$-treated $\mathrm{BiVO}_{4}$ (red, dashed) measured in a $0.5 \mathrm{M}$ phosphate buffer $(\mathrm{pH}$ 7.2) under AM 1.5G illumination using a three-electrode cell. Grey dashed lines show dark current of $\mathrm{N}_{2}$-treated $\mathrm{BiVO}_{4} / \mathrm{FeOOH} / \mathrm{NiOOH}$. (b) $\mathrm{J}-\mathrm{V}$ plot and (c) $\mathrm{ABPE}$ of $\mathrm{N}_{2}$-treated $\mathrm{BiVO}_{4} / \mathrm{FeOOH} / \mathrm{NiOOH}$ obtained using a two-electrode cell for solar water splitting (CE: counter electrode).

(d) Detection of $\mathrm{H}_{2}$ (blue) and $\mathrm{O}_{2}$ (red) produced by $\mathrm{N}_{2}$-treated $\mathrm{BiVO}_{4} / \mathrm{FeOOH} / \mathrm{NiOOH}$ at $0.6 \mathrm{~V}$ versus counter electrode. The red dashed line represents the amount of $\mathrm{O}_{2}$ calculated assuming $100 \%$ Faradaic efficiency. (e) J-t plots of $\mathrm{N}_{2}$-treated $\mathrm{BiVO}_{4}$ for sulfite oxidation (blue) and $\mathrm{N}_{2}$-treated $\mathrm{BiVO}_{4} / \mathrm{FeOOH} / \mathrm{NiOOH}$ for water oxidation (red) at $0.6 \mathrm{~V}$ versus RHE.

out in a $0.1 \mathrm{M} \mathrm{FeSO}_{4}$ solution ( $\mathrm{pH} 3.2-3.8$ ) while gently stirring. Before photodeposition, the solution was purged with nitrogen gas for $1 \mathrm{~h}$. An undivided three-electrode cell composed of a $\mathrm{N}_{2}$-treated $\mathrm{BiVO}_{4}$ working electrode, a Pt counter electrode, and a $\mathrm{Ag} / \mathrm{AgCl}(4 \mathrm{M} \mathrm{KCl})$ reference electrode, was used. $\mathrm{A}$ $300 \mathrm{~W}$ Xe arc lamp (Oriel Newport) with an AM 1.5G filter, neutral density filters and a water filter (IR filter) was used as the light source. The light was illuminated through the FTO contact (back-side illumination) and the light intensity at the FTO surface was adjusted to be $1 \mathrm{~mW} \mathrm{~cm}^{-2}$ using a research radiometer (International Light, IL 1700) coupled with a thermopile detector (International Light, SED623/H/N/K15). To facilitate photodeposition, an external bias of ca. $0.26-0.31 \mathrm{~V}$ versus $\mathrm{Ag} / \mathrm{AgCl}(4 \mathrm{M} \mathrm{KCl})$, which was the open circuit potential of the $\mathrm{N}_{2}$-treated $\mathrm{BiVO}_{4}$ electrodes in the solution in dark, was applied using a potentiostat (BioLogic SP-200). After the photodeposition of $\mathrm{FeOOH}$, the electrodes were rinsed with DI water and dried at room temperature. Among various photodeposition times tested (that is, 10-60 min), deposition for $c a .45 \mathrm{~min}$ (passing a total charge of $65-70 \mathrm{mC} \mathrm{cm}^{-2}$ ) was identified to be optimum to maximize photocurrent generation for water oxidation.
Photodeposition of $\mathrm{NiOOH}$ was carried out on the $\mathrm{N}_{2}$-treated $\mathrm{BiVO}_{4} / \mathrm{FeOOH}$ electrodes using a $0.1 \mathrm{M} \mathrm{NiSO}_{4}$ solution with $\mathrm{pH}$ adjusted to $6.3-7.0$ by adding $\mathrm{NaOH}$. To facilitate photodeposition, an external bias of ca. $0.12-0.16 \mathrm{~V}$ versus $\mathrm{Ag} / \mathrm{AgCl}(4 \mathrm{M} \mathrm{KCl})$, which was the open circuit potential of the $\mathrm{N}_{2}$-treated $\mathrm{BiVO}_{4} / \mathrm{FeOOH}$ electrodes in the solution in dark, was applied. The optimum deposition time was ca. $25 \mathrm{~min}$ (passing a total charge of $20-22 \mathrm{mC} \mathrm{cm}^{-2}$ ). After photodeposition of $\mathrm{NiOOH}, \mathrm{NiOOH}$ was also electrochemically deposited by applying $+1.2 \mathrm{~V}$ versus $\mathrm{Ag} / \mathrm{AgCl}(4 \mathrm{M} \mathrm{KCl})$ for $1 \mathrm{~min}$. This was to deposit $\mathrm{NiOOH}$ on any bare $\mathrm{BiVO}_{4}$ or FTO surfaces exposed to the electrolyte. After deposition, the electrodes were washed with DI water and dried at room temperature. The molar ratio of $\mathrm{Fe} / \mathrm{Ni}$ in optimized $\mathrm{N}_{2}$-treated $\mathrm{BiVO}_{4} / \mathrm{FeOOH} / \mathrm{NiOOH}$ electrodes was estimated to be $4.92 \pm 1.87$ by energy-dispersive spectroscopy (using three samples at the $95 \%$ confidence level).

Characterization. The purity and crystal structure of the synthesized electrodes, pristine $\mathrm{BiVO}_{4}$ and $\mathrm{N}_{2}$-treated $\mathrm{BiVO}_{4}$, were examined by X-ray diffraction (Bruker D8 Advanced PXRD, $\lambda=1.5418 \AA$, $298 \mathrm{~K}$, Ni-filtered $\mathrm{Cu} \mathrm{K}_{\alpha}$-radiation). The crystal morphologies of the electrodes were examined with scanning electron microscopy using a LEO 1530 microscope at an accelerating voltage of $5 \mathrm{kV}$. The chemical composition of $\mathrm{Bi} / \mathrm{V}$ in the $\mathrm{BiVO}_{4}$ electrodes was confirmed to be $0.98 \pm 0.02$ by a Hitachi S3400-N microscope equipped with an energy-dispersive X-ray spectrometer (Thermo Fisher Scientific Inc.). For the quantitative analysis of the amount of nitrogen doping in $\mathrm{N}_{2}$-treated $\mathrm{BiVO}_{4}$, EPMA employing a CAMECA SX-50 apparatus was conducted. In sample preparation, the anode material on the FTO film was scraped off and placed on a carbon tape. A precisely quantitative analysis of nitrogen was achieved by calibration using a high-purity GaN as a standard reference. Ultraviolet-visible absorption spectra were obtained on a Cary 5000 Ultraviolet-visible spectrophotometer (Agilent), in which the sample electrode was fixed in the centre of an integrating sphere to measure all light reflected and transmitted to accurately assess the absorbance. FTO glass was used as the reference for these absorption measurements. XPS spectra were recorded using a K-Alpha X-ray photoelectron spectrometer (Thermo Scientific Inc.) equipped with a monochromated $\mathrm{Al} \mathrm{K}$ line as the $\mathrm{X}$-ray source. The binding energies were calibrated with respect to the residual C (1s) peak at $284.6 \mathrm{eV}$. Raman spectra of the pristine $\mathrm{BiVO}_{4}$ and the $\mathrm{N}_{2}$-treated $\mathrm{BiVO}_{4}$ electrodes were recorded at room temperature using a Raman spectrometer (Thermo Scientific DXR smart Raman spectrometer). A red laser $(780 \mathrm{~nm})$ was used as excitation source. The electrodes were placed such that the $\mathrm{BiVO}_{4}$ and the $\mathrm{N}_{2}$-treated $\mathrm{BiVO}_{4}$ side of electrodes faced the laser source. Capacitance measurements for Mott-Schottky plots were obtained using a SP-200 potentiostat/EIS (BioLogic Science Instrument) with an EC-Lab software package. A sinusoidal modulation of $10 \mathrm{mV}$ was applied at frequencies of 0.5 and $1 \mathrm{kHz}$. The three-electrode setup was used in a $0.5 \mathrm{M}$ phosphate buffer solution ( $\mathrm{pH}$ 7.2). All electrodes were masked with epoxy resin to expose the same geometrical area (ca. $0.1 \mathrm{~cm}^{2}$ ) for this measurement. The zeta potential measurements of pristine $\mathrm{BiVO}_{4}$ and $\mathrm{N}_{2}$-treated $\mathrm{BiVO}_{4}$ were conducted using a zeta potential analyser (Micromeritics NanoPlus-2), which measures electrophoretic mobilities of charged particles to calculate zeta potentials. This was to compare Helmholtz layer potential drop $\left(V_{\mathrm{H}}\right)$ of the pristine and $\mathrm{N}_{2}$-treated $\mathrm{BiVO}_{4}$ electrodes (equation 1), which is another factor that affects the position of flatband potential $\left(E_{\mathrm{FB}}\right)$ (equation 2$)^{35}$.

$$
\begin{gathered}
V_{\mathrm{H}}=0.059\left(\mathrm{pH}_{\mathrm{PZZP}}-\mathrm{pH}\right) \\
E_{\mathrm{FB}}(\mathrm{NHE})=\phi_{\mathrm{SC}}+V_{\mathrm{H}}-4.5
\end{gathered}
$$

The point of zero zeta potential ( $\mathrm{pH}_{\mathrm{PZZP}}$ ) of $\mathrm{BiVO}_{4}$ and $\mathrm{N}_{2}$-treated $\mathrm{BiVO}_{4}$ could not be directly measured because $\mathrm{BiVO}_{4}$ is not chemically stable near its $\mathrm{pH}_{\text {PZZP. }}$ However, zeta potentials at $\mathrm{pH} 7.2$ solution could still be used to qualitatively compare the $\mathrm{pH}_{\mathrm{PZZPS}}$ of $\mathrm{BiVO}_{4}$ and $\mathrm{N}_{2}$-treated $\mathrm{BiVO}_{4}$ and their effects on $\mathrm{E}_{\mathrm{FB}}$. For the zeta potential measurement, $\mathrm{BiVO}_{4}$ and $\mathrm{N}_{2}$-treated $\mathrm{BiVO}_{4}$ nanoparticles were scratched off the electrode substrates and dispersed in a $0.5 \mathrm{M}$ phosphate buffer solution ( $\mathrm{pH}$ 7.2) using sonication.

Photoelectrochemical measurements. Photoelectrochemical performances of photoanodes prepared in this work were evaluated in a typical undivided three-electrode configuration using a SP-200 potentiostat/EIS (BioLogic Science Instrument). The simulated solar illumination was obtained by passing light from a $300 \mathrm{~W}$ Xe arc lamp (Oriel Newport) through a water filter (IR filter)/neutral density filters/an AM 1.5G filter. Illumination through the FTO side (back-side illumination) was used. The power density of the incident light was calibrated to $100 \mathrm{~mW} \mathrm{~cm}^{-2}$ at the surface of the FTO substrate (before the light penetrates FTO) by using a research radiometer (International Light, IL 1700) coupled with a thermopile detector (International Light, SED623/H/N/K15) and a NREL certified reference cell (Photo Emission Tech., Inc.). The beam passed through an optical fibre and the active area of the sample exposed to electrolyte is between ca. $0.1-0.2 \mathrm{~cm}^{2}$. Photocurrent measurements were performed in a $0.5 \mathrm{M}$ potassium phosphate $\left(\mathrm{KH}_{2} \mathrm{PO}_{4}\right)$ buffer solution ( $\mathrm{pH}$ 7.2) with or without $1 \mathrm{M}$ sodium sulfite $\left(\mathrm{Na}_{2} \mathrm{SO}_{3}\right)$ as a hole scavenger. Before measurements, the electrolyte was thoroughly deaerated by purging with nitrogen. Photocurrents were monitored either while sweeping the potential to the positive direction with a scan rate of $10 \mathrm{mV} \mathrm{s}^{-1}$ or while applying a constant bias. The mean values and confidence intervals of 
photocurrent density and electron-hole separation yield provided in the text and Supplementary Table 1 were determined using measurements on three different samples at the $95 \%$ confidence level. While all measurements were carried out using a $\mathrm{Ag} / \mathrm{AgCl}(4 \mathrm{M} \mathrm{KCl})$ reference electrode, all results in this work were presented against the RHE for ease of comparison with $\mathrm{H}_{2}$ and $\mathrm{O}_{2}$ redox levels and other reports that used electrolytes with different $\mathrm{pH}$ conditions. The conversion between potentials versus $\mathrm{Ag} / \mathrm{AgCl}$ and versus $\mathrm{RHE}$ is determined using the equation below.

$$
\begin{aligned}
& E(\text { versus } \mathrm{RHE})=E(\text { versus } \mathrm{Ag} / \mathrm{AgCl})+E_{\mathrm{Ag} / \mathrm{AgCl}}(\text { reference })+0.0591 \mathrm{~V} \times \mathrm{pH} \\
& \left(E_{\mathrm{Ag} / \mathrm{AgCl}}(\text { reference })=0.1976 \mathrm{~V} \text { versus } \mathrm{NHE} \text { at } 25^{\circ} \mathrm{C}\right)
\end{aligned}
$$

IPCE at each wavelength was determined using illumination from a $300 \mathrm{~W}$ Xe arc lamp (Oriel Newport) passed through an AM 1.5G filter, neutral density filters, and a water filter to approximate the output of the sun. Monochromatic light was produced using an Oriel Cornerstone 130 monochromator with a 10-nm bandpass. The intensity of incident light was measured using a research radiometer (International Light, IL 1700) with a calibrated silicon photodiode detector (International Light, SED033). IPCE was measured in $0.5 \mathrm{M}$ phosphate buffer ( $\mathrm{pH}$ 7.2) with the same three-electrode setup described above for photocurrent measurements, using a Princeton Applied Research Potentiostat/Galvanostat model $263 \mathrm{~A}$ to apply $0.6 \mathrm{~V}$ versus RHE. APCE was obtained by dividing the IPCE by the light harvesting efficiency at each wavelength using the following equations (equations 4 and 5).

$$
\operatorname{APCE}(\%)=\operatorname{IPCE}(\%) / \mathrm{LHE}
$$

$$
\text { LHE }=1-10^{-A_{(\lambda)}}\left(A_{(\lambda)}: \text { absorbance at wavelength } \lambda\right)
$$

To calculate respective $J_{\max } \mathrm{s}$ (maximum photocurrent density achievable assuming $100 \%$ IPCE for photons with energy $\geq E_{\mathrm{g}}$ ) of $\mathrm{BiVO}_{4}$ and $\mathrm{N}_{2}$-treated $\mathrm{BiVO}_{4}$, the National Renewable Energy Laboratory (NREL) reference solar spectral irradiance at AM 1.5G (radiation energy $\left(\mathrm{W} \mathrm{m}^{-2} \mathrm{~nm}^{-1}\right.$ ) versus wavelength $(\mathrm{nm})$ ) was first converted to the solar energy spectrum in terms of number of photons $\left(\mathrm{s}^{-1} \mathrm{~m}^{-2} \mathrm{~nm}^{-1}\right)$ versus wavelength $(\mathrm{nm})^{50}$. Then, the number of photons above the bandgap energy of each sample shown in this study was calculated using a trapezoidal integration (in $10 \mathrm{~nm}$ increments) of the spectrum and was converted to the current density $\left(\mathrm{mA} \mathrm{cm}^{-2}\right) . J_{\max } \mathrm{s}$ for pristine $\mathrm{BiVO}_{4}$ and $\mathrm{N}_{2}$-treated $\mathrm{BiVO}_{4}$ were 6.47 and $9.12 \mathrm{~mA} \mathrm{~cm}^{-2}$, respectively.

To calculate $J_{\text {abs }}$ (photocurrent assuming 100\% APCE), the light harvesting efficiency at each wavelength was multiplied during each step of the trapezoidal integration. Using these calculations, $J_{\text {abs }} s$ for pristine $\mathrm{BiVO}_{4}$ and $\mathrm{N}_{2}$-treated $\mathrm{BiVO}_{4}$ were calculated to be $4.44 \pm 0.05 \mathrm{~mA} \mathrm{~cm}^{-2}$ and $5.30 \pm 0.07 \mathrm{~mA} \mathrm{~cm}^{-2}$, respectively.

Photocurrent density obtained for sulfite oxidation was used to calculate the electron-hole separation yield ( $=$ the yield of the photogenerated holes that reach the surface), $\phi_{\text {sep }}$, using the following equation (equation 6), where $J_{\mathrm{PEC}}$ is the measured photocurrent density and $\phi_{\mathrm{ox}}$ is the yield of the surface reaching holes that are injected into the solution species ${ }^{51,52}$. For sulfite oxidation with extremely fast oxidation kinetics, surface recombination is negligible and $\phi_{\mathrm{ox}}$ is $\sim 1$.

Therefore, $\phi_{\text {sep }}$ is obtained by dividing $J_{\text {PEC }}$ by $J_{\text {abs }}$.

$$
J_{\mathrm{PEC}}=J_{\mathrm{abs}} \times \phi_{\text {sep }} \times \phi_{\mathrm{ox}}
$$

The ABPE was calculated from the $J-V$ curves obtained from a two-electrode systems assuming $100 \%$ Faradaic efficiency using the following equation, where $\mathrm{J}$ is the photocurrent density, $V_{\text {bias }}$ is the applied bias between working electrode $\left(\mathrm{BiVO}_{4}\right.$ photoanode) and counter electrode (Pt cathode) and $P_{\text {in }}$ is the incident illumination power density (AM $1.5 \mathrm{G}, 100 \mathrm{~mW} \mathrm{~cm}^{-2}$ ) (equation 7) ${ }^{12}$.

$$
\operatorname{ABPE}(\%)=\left[\frac{J\left(\mathrm{~mA} \mathrm{~cm}^{-2}\right) \times\left(1.23-V_{\text {bias }}\right)(\mathrm{V})}{P_{\text {in }}\left(\mathrm{mA} \mathrm{cm}^{-2}\right)}\right]_{\mathrm{AM} 1.5 \mathrm{G}} \times 100
$$

$\mathrm{O}_{2}$ measurements were performed using an Ocean Optics fluorescence-based oxygen sensor (Neofox, FOSPOR-R 1/16"). The probe measures the $\mathrm{O}_{2}$ content in the headspace as mole $\%$, which was converted to micromoles after adjusting for the $\mathrm{O}_{2}$ dissolved in solution using Henry's Law. $\mathrm{O}_{2}$ measurements were performed with an undivided two-electrode cell using a custom built and airtight 3-neck $50 \mathrm{ml}$ round-bottom flask with a $\mathrm{N}_{2}$-treated $\mathrm{BiVO}_{4} / \mathrm{FeOOH} / \mathrm{NiOOH}$ working electrode and a Pt mesh counter electrode. $\mathrm{O}_{2}$ measurements were carried out while applying $0.6 \mathrm{~V}$ between the working electrode and the counter electrode. The experiment of oxygen evolution was run for $3 \mathrm{~h}$ after a 15 -min waiting period at open circuit. The 15 min periods before and after the oxygen evolution step were used to calculate the $\mathrm{O}_{2}$ leak rate of the cell. The amount of $\mathrm{O}_{2}$ detected was divided by the amount of $\mathrm{O}_{2}$ expected calculated from photocurrent assuming $100 \%$ Faradaic efficiency to calculate the true Faradaic efficiency or the photocurrent-to- $\mathrm{O}_{2}$ conversion efficiency.

$\mathrm{H}_{2}$ production measurements were carried out by applying $0.6 \mathrm{~V}$ between the working electrode and the counter electrode (two-electrode system) under the same condition used in $\mathrm{O}_{2}$ measurement, using GC (SRI Instruments) to analyze the headspace. The amount of $\mathrm{H}_{2}$ gas evolved was determined by taking $100 \mu \mathrm{l}$ of gas from the headspace of the cell using a syringe and injecting it into the gas-sampling loop of the GC every one hour. The GC was equipped with a packed MolSieve
$13 \mathrm{X}$ column. Helium (Airgas, ultra high purity) was used as the carrier gas. A helium ionization detector was used to quantify hydrogen concentration.

All the confidence intervals for any quantity shown in the main text were calculated using the $95 \%$ confidence level.

DFT calculations for nitrogen substitutions. Calculations were performed with the Quantum Espresso Package ${ }^{53}$ using DFT with the generalized gradient approximation and the parameterization proposed by $\mathrm{PBE}^{36}$. We used ultrasoft pseudo-potentials, where $(3 s, 3 p)$ electrons of $\mathrm{V}$ were included in the valence partition. A kinetic energy cutoff of 40 and 240 Ry for the wavefunction and charge density, respectively, and $(4 \times 3 \times 6)$ Monkhorst-Pack k-point grids were used in geometry optimizations, and $(5 \times 5 \times 7) \mathrm{k}$-point grids were used for density of states calculations. In our super cell calculations, both internal geometry and cell size were fully optimized for pristine $\mathrm{BiVO}_{4}$ and only the internal geometry was optimized for $\mathrm{N}$-doped $\mathrm{BiVO}_{4}$.

We obtained a bandgap of $2.25 \mathrm{eV}$ for pristine $\mathrm{BiVO}_{4}$, underestimating the experimental optical gap by only $\sim 0.2 \mathrm{eV}$. The good agreement between the computed bandgap and the experimental optical gap is due to a partial cancelation of errors, encompassing the PBE underestimation of gaps, the neglect of excitonic effects (the exciton binding energy is estimated to be $\sim 0.23 \mathrm{eV}$ ) and spin-orbit coupling ( $\sim 40 \mathrm{meV}$, as obtained by fully relativistic calculations). The exciton binding energy was estimated using a hydrogen-like model, $E_{\mathrm{b}}=\frac{m e^{4}}{2 \hbar^{2} \varepsilon_{\infty}^{2}}\left(E_{\mathrm{b}}\right.$ : the binding energy of the first excitonic state; $m$ : the effective mass, $m=1 /\left(\frac{1}{m_{e}}+\frac{1}{m_{h}}\right)$; $\varepsilon_{\infty}$ : the high-frequency dielectric constant).

Our results for the band structure of the $\mathrm{N}$-doped oxide $(12.5 \% \mathrm{O}$ atoms replaced with $\mathrm{N}$, equivalent to the stoichiometry $\mathrm{BiVO}_{3.5} \mathrm{~N}_{0.5}$ ) are shown in Supplementary Fig. 5 for the spin-polarized configuration, which was found to be energetically favoured. The 1:1 substitution of $\mathrm{O}$ with $\mathrm{N}$ cannot compensate for the charge change caused by the loss of an $\mathrm{O}$ atom. (Oxygen has 6 valence electrons and $\mathrm{N}$ has 5 valence electrons.) The resulting presence of excess holes leads to two localized empty bands (labelled ' $a$ ' in Supplementary Fig. 5b) inside the bandgap of $\mathrm{BiVO}_{4}$. The energy of the localized mid-gap states is sensitive to the location of $\mathrm{N}$ atoms in the lattice (it varies by $0.5 \mathrm{eV}$ depending on the position of the $\mathrm{N}$ atom). The bandgap of $\mathrm{N}$-doped $\mathrm{BiVO}_{4}$, defined as the energy difference between the top of the valence band (level labelled ' $b$ ' in Supplementary Fig. 5b) and the bottom of the conduction band (level labelled 'c' in Supplementary Fig. 5b), is $1.77 \mathrm{eV}$ at $12.5 \% \mathrm{~N}$-doping, i.e. $0.48 \mathrm{eV}$ lower than that of pristine $\mathrm{BiVO}_{4}$.

These bands are no longer present in the case of $\mathrm{N}$ substitution accompanied by charge-balancing $\mathrm{O}$ vacancies, which will serve as electron donors and compensate for the excess holes present due to $\mathrm{N}$ substitution (Fig. 4a). We also show the band structure of the $\mathrm{N}$-doped oxide $(12.5 \% \mathrm{O}$ replaced with $\mathrm{N})$ when we artificially added an electron per nitrogen to compensate for excess holes generated from charge-imbalanced N substitution (Supplementary Fig. 6). (In other words, we artificially substituted $\mathrm{O}$ with $\mathrm{N}^{-}$). Our results show that the bandgap of $\mathrm{N}$ doped $\mathrm{BiVO}_{4}$ is $1.86 \mathrm{eV}$ at $12.5 \% \mathrm{~N}$-doping, that is, $0.39 \mathrm{eV}$ lower than that of pristine $\mathrm{BiVO}_{4}$. However, in this case the mid-gap states are no longer present. The projected density of states in Supplementary Fig. 6a shows that there is significant hybridization between $\mathrm{N} 2 p$ and $\mathrm{O} 2 p$ states at the top of the valence band.

DFT calculations for oxygen vacancies. Calculations were performed using spin-polarized DFT and the PBE approximation. We also included Hubbard $U$-corrections to the $d$ electrons of $\mathrm{V}(U=2.7 \mathrm{eV})$ following a previous study by Park et al. ${ }^{17}$. All $\mathrm{O}$ vacancies discussed in this study were created by removing neutral $\mathrm{O}$ atoms. At the PBE level of theory, when 1.5 or $6 \% \mathrm{O}$ vacancies were introduced in the system, we observed the appearance of one isolated band inside the bandgap of $\mathrm{BiVO}_{4}$ (shown in Supplementary Fig. 7), whose bandgap and insulating character were however not changed. We found that the two electrons from $\mathrm{O}$ vacancies were ionized and localized on a $\mathrm{V}$ and a $\mathrm{Bi}$ atom, at the PBE level of theory, as shown in Supplementary Fig. 7. This makes the charge state of the O vacancy $q=+2$. Within $\mathrm{PBE}+U$, the isolated gap states observed within PBE split into two bands, with the spin density mostly localized on $\mathrm{V}$ atoms for both states, as shown in Supplementary Fig. 8. The inclusion of Hubbard $U$ has several effects; it leads to (i) localization of the excess electrons only on $\mathrm{V}$ and (ii) an increase in the energy difference between the filled gap states created by oxygen vacancies and the conduction band minimum (mainly composed of $\mathrm{V} d$ states) by $0.2 \mathrm{eV}$, compared with PBE; such differences increase with the magnitude of $U$, however the charge density remains localized on $\mathrm{V}$ atoms for all $U$ values.

Small polaron binding energy and mobility. The small polaron binding energy $\left(W_{\mathrm{p}}\right)$ can be computed ${ }^{42}$ as $W_{\mathrm{p}}=\frac{e^{2}}{2 \varepsilon_{\mathrm{p}} r_{\mathrm{p}}}$ where $\frac{1}{\varepsilon_{\mathrm{p}}}=\frac{1}{\varepsilon_{\infty}}-\frac{1}{\varepsilon_{0}}, \varepsilon_{\infty}$ and $\varepsilon_{0}$ are the high frequency and static dielectric constant respectively; the $r_{\mathrm{p}}$ is the small polaron radius. The small polaron radius is on the order of magnitude of $1 \AA$, and it can be approximately computed as $r_{\mathrm{p}}=\frac{1}{2}\left(\frac{\pi}{6}\right)^{1 / 3} \bar{a}$, where $\bar{a}^{-3}$ is the number of centres per unit volume. The computed $\varepsilon_{\infty}$ and $\varepsilon_{0}$ are 6.9 and 52, respectively, for undoped $\mathrm{BiVO}_{4}$ and we obtain $r_{\mathrm{p}}=1.73 \AA$ from our DFT calculations (at the PBE level of theory), which gives a polaron binding energy of $0.52 \mathrm{eV}$. The model adopted here yields a lower bound for the polaron binding energy. The polaron binding energy is 
non-negligible compared with $k T$; hence the formation of small polarons at $\mathrm{V}$ sites is energetically favoured.

Recent resistivity $(\rho)$ measurements ${ }^{39}$ on single crystal n-doped $\mathrm{BiVO}_{4}$ show that between 250 and $400 \mathrm{~K}$, the resistivity data perfectly fit to the adiabatic small polaron model ${ }^{42}: \rho \propto T \exp \left(\frac{W_{\mathrm{H}}}{k T}\right)$, where $T$ is the absolute temperature, $k$ is the Boltzmann's constant and $W_{\mathrm{H}}$ is the polaron hopping activation energy. $W_{\mathrm{H}}$ may be approximated by $W_{\mathrm{H}}=\frac{e^{2}}{4 \varepsilon_{\mathrm{p}}}\left(\frac{1}{r_{\mathrm{p}}}-\frac{1}{R}\right)$, where $\varepsilon_{\mathrm{p}}$ and $r_{\mathrm{p}}$ have been defined above ${ }^{42,54}$, in the formula giving the polaron binding energy. $R$ is the distance between small polaron hopping centres. We found that $\varepsilon_{\infty}$ changed from 6.9 (pristine $\mathrm{BiVO}_{4}$ ) to 6.2 (doped $\mathrm{BiVO}_{4}$ with $6 \% \mathrm{~N}$ substitution and $3 \% \mathrm{O}$ vacancies) and $\varepsilon_{0}$ changed from 52 (pristine $\mathrm{BiVO}_{4}$ ) to 27 (doped $\mathrm{BiVO}_{4}$ ). The significant lowering of $\varepsilon_{0}$ stems from the presence of several higher phonon vibrational frequencies present after $\mathrm{N}$-doping $\left(\varepsilon_{0}\right.$ is inversely proportional to the square of the phonon vibrational frequencies). Overall, the $W_{\mathrm{H}}$ is lowered by $1.1 \%$ upon doping, which leads to an improvement in the mobility $\mu$ by $\sim 25 \%$ according to $\mu \propto \frac{1}{T} \exp \left(\frac{-W_{\mathrm{H}}}{k T}\right)$.

DFT calculations for charge-balanced $\mathbf{N}$-doped $\mathrm{BiVO}_{4}$. Projected density of states of $\mathrm{BiVO}_{4}$ with charge-balanced $\mathrm{N}$-doping $(9 \% \mathrm{O}$ replaced with $6 \% \mathrm{~N}$ and $3 \%$ $O$ vacancy) obtained within DFT-PBE $+U$ is shown below (Supplementary Fig. 9). In this case, due to the relative proportion of substitutional $\mathrm{N}$ atoms and $\mathrm{O}$ vacancies, electrons from $\mathrm{O}$ vacancies compensate for extra holes generated by $\mathrm{N}$ substitution, balancing the charge. For the charge-balanced $\mathrm{N}$-doping, we have also carried out calculations to study the stability of an $\mathrm{N}$ dopant and $\mathrm{O}$ vacancy complex, by comparing the total energy of a configuration where the $\mathrm{O}$ vacancy is far away from a $\mathrm{N}$ dopant (at a $\sim 7-10 \AA$ distance) to that of a configuration where the $\mathrm{O}$ vacancy is close to a $\mathrm{N}$ dopant (at a $\sim 2 \AA$ distance) in which case $\mathrm{N}$ dopants and $\mathrm{O}$ vacancies interact strongly to form a complex; we used a super cell with two $\mathrm{N}$ dopants and one extra $\mathrm{O}$ vacancy. We found that the total energy is lowered by $0.26 \mathrm{eV}$ when forming a $\mathrm{N}$ dopant-O vacancy complex, which means that the complex defect is thermodynamically preferred; however, the formation of this complex may be kinetically limited, as the $\mathrm{N}$ dopant or $\mathrm{O}$ vacancy have to migrate towards each other to form the complex. We note that the band structure of the sample where the $\mathrm{N}$ dopant-O vacancy complex is present is more dispersive than that where the $\mathrm{N}$ dopants and $\mathrm{O}$ vacancies are far apart and the bandgap is $0.2 \mathrm{eV}$ higher.

DFT calculations for $\mathbf{N}$-doped $\mathrm{BiVO}_{4}$ with excess oxygen vacancies. We performed spin-polarized DFT with the PBE approximation calculations of $\mathrm{BiVO}_{4}$ with additional $\mathrm{O}$ vacancies, in excess to those necessary to charge $\mathrm{N}$-substituted centres (doping concentration of $6 \% \mathrm{~N}$ and $6 \% \mathrm{O}$ vacancies, see Supplementary Fig. 10). As shown in Supplementary Fig. 10, the N $2 p$ states lie at the top of valence band and are mixed with $\mathrm{O} 2 p$ states; the presence of $\mathrm{N}$ leads to an increase of the VBM energy and a decrease of the bandgap of $\mathrm{BiVO}_{4}$ by $0.3 \mathrm{eV}$, (The bandgap here is defined as the energy difference between the bottom of the conduction band above the Fermi level and the top of the valence band (mixed $\mathrm{O}$ and $\mathrm{N} 2 p$ states)). In addition, there are filled gap states due to excess electrons from additional $\mathrm{O}$ vacancies, which are localized around $\mathrm{V}$ atoms, even with $U=0$. This is probably due to lattice distortions occurring in the presence of $\mathrm{N}$ and favouring localization of electronic states. The major findings in different doping cases are summarized in Supplementary Table 2.

\section{References}

1. U.S. Department of Energy, Hydrogen and fuel cells program. Hydrogen and Fuel Cell Activities, Progress, and Plans. Available at http://www.hydrogen. energy.gov/congress_reports.html (2005).

2. United Nations Development Program. World Energy Assessment Report: Energy and the Challenge of Sustainability (United Nations, 2003).

3. Lewis, N. S. \& Nocera, D. G. Powering the planet: chemical challenges in solar energy utilization. Proc. Natl Acad. Sci. USA 103, 15729-15735 (2006).

4. Vesborg, P. C. K. \& Jaramillo, T. F. Addressing the terawatt challenge: scalability in the supply of chemical elements for renewable energy. RSC $A d v . \mathbf{2}$, 7933-7947 (2012).

5. Grätzel, M. Photoelectrochemical cells. Nature 414, 338-344 (2001).

6. Abe, R. Recent progress on photocatalytic and photoelectrochemical water splitting under visible light irradiation. J. Photochem. Photobiol. C Photochem. Rev. 11, 179-209 (2010).

7. Li, Z., Luo, W., Zhang, M., Feng, J. \& Zou, Z. Photoelectrochemical cells for solar hydrogen production: current state of promising photoelectrodes, methods to improve their properties, and outlook. Energy Environ. Sci. 6, 347-370 (2013).

8. Kudo, A., Omori, K. \& Kato, H. A novel aqueous process for preparation of crystal form-controlled and highly crystalline $\mathrm{BiVO}_{4}$ powder from layered vanadates at room temperature and its photocatalytic and photophysical properties. J. Am. Chem. Soc. 121, 11459-11467 (1999).

9. Park, Y., McDonald, K. J. \& Choi, K.-S. Progress in bismuth vanadate photoanodes for use in solar water oxidation. Chem. Soc. Rev. 42, 2321-2337 (2013).
10. Huang, Z. -F., Pan, L., Zou, J. -J., Zhang, X. \& Wang, L. Nanostructured bismuth vanadate-based materials for solar-energy-driven water oxidation: a review on recent progress. Nanoscale 6, 14044-14063 (2014).

11. Kim, T. W. \& Choi, K. S. Nanoporous $\mathrm{BiVO}_{4}$ photoanodes with dual-layer oxygen evolution catalysts for solar water splitting. Science 343, 990-994 (2014).

12. Chen, Z. et al. Accelerating materials development for photoelectrochemical hydrogen production: standards for methods, definitions, and reporting protocols. J. Mater. Res. 25, 3-16 (2010).

13. Murphy, B. et al. Efficiency of solar water splitting using semiconductor electrodes. Int. J. Hydrogen Energy 31, 1999-2017 (2006).

14. Vayssieres, L. On Solar Hydrogen and Nanotechnology (John Wiley \& Sons (Asian), 2009).

15. Abdi, F. F. et al. Efficient solar water splitting by enhanced charge separation in a bismuth vanadate-silicon tandem photoelectrode. Nat. Commun. 4, 2195 (2013).

16. Park, Y., Kang, D. \& Choi, K.-S. Marked enhancement in electron-hole separation achieved in the low bias region using electrochemically prepared Mo-doped $\mathrm{BiVO}_{4}$ photoanodes. Phys. Chem. Chem. Phys. 16, 1238-1246 (2014).

17. Park, H. S. et al. Factors in the metal doping of $\mathrm{BiVO}_{4}$ for improved photoelectrocatalytic activity as studied by scanning electrochemical microscopy and first-principles density-functional calculation. J. Phys. Chem. C 115, 17870-17879 (2011).

18. Jo, W. J. et al. Phosphate doping into monoclinic $\mathrm{BiVO}_{4}$ for enhanced photoelectrochemical water oxidation activity. Angew. Chem. Int. Ed. 51, 3147-3151 (2012).

19. Wang, M., Liu, Q., Che, Y., Zhang, L.F. \& Zhang, D. Characterization and photocatalytic properties of $\mathrm{N}$-doped $\mathrm{BiVO}_{4}$ synthesized via a sol-gel method. J. Alloys Compd. 548, 70-76 (2013).

20. Yin, C. et al. One step fabrication of C-doped $\mathrm{BiVO}_{4}$ with hierarchical structures for a high-performance photocatalyst under visible light irradiation. J. Mater. Chem. A 1, 8367-8378 (2013).

21. Cooper, J. K. et al. Electronic structure of monoclinic $\mathrm{BiVO}_{4}$. Chem. Mater. 26, 5365-5373 (2014).

22. Hoang, S., Cuo, S., Hahn, N. T., Bard, A. J. \& Mullins, B. Visible light driven photoelectrochemical water oxidation on nitrogen-modified $\mathrm{TiO}_{2}$ nanowires. Nano Lett. 12, 26-32 (2012).

23. Li, Y. et al. Vertically aligned $\mathrm{Ta}_{3} \mathrm{~N}_{5}$ nanorod arrays for solar-driven photoelectrochemical water splitting. Adv. Mater. 25, 125-131 (2013).

24. Higashi, M., Domen, K. \& Abe, R. Fabrication of efficient $\mathrm{TaON}$ and $\mathrm{Ta}_{3} \mathrm{~N}_{5}$ photoanodes for water splitting under visible light irradiation. Energy Environ. Sci. 4, 4138-4147 (2011).

25. Yang, X. et al. Nitrogen-doped $\mathrm{ZnO}$ nanowire arrays for photoelectrochemical water splitting. Nano Lett. 9, 2331-2336 (2009).

26. Wang, J. et al. Origin of photocatalytic activity of nitrogen-doped $\mathrm{TiO}_{2}$ nanobelts. J. Am. Chem. Soc. 131, 12290-12297 (2009).

27. Yu, J. \& Kudo, A. Effects of structural variation on the photocatalytic performance of hydrothermally synthesized $\mathrm{BiVO}_{4}$. Adv. Funct. Mater. 16, 2163-2169 (2006).

28. Galembecka, A. \& Alves, O. L. $\mathrm{BiVO}_{4}$ thin film preparation by metalorganic decomposition. Thin Solid Films 365, 90-93 (2000).

29. Liu, D. et al. $\mathrm{V}_{2} \mathrm{O}_{5}$ xerogel electrodes with much enhanced lithium-ion intercalation properties with $\mathrm{N}_{2}$ annealing. J. Mater. Chem. 19, 8789-8795 (2009).

30. Bhaway, S. M. et al. Mesoporous carbon-vanadium oxide films by resol-assisted, triblock copolymer-templated cooperative self-assembly. ACS Appl. Mater. Interfaces 6, 19288-19298 (2014).

31. Wang, G. et al. Computational and photoelectrochemical study of hydrogenated bismuth vanadate. J. Phys. Chem. C 117, 10957-10964 (2013).

32. Qin, D.-D., Wang, T., Song, Y.-M. \& Taob, C.-L. Reduced monoclinic $\mathrm{BiVO}_{4}$ for improved photoelectrochemical oxidation of water under visible light. Dalton Trans. 42, 6736-6744 (2013).

33. Kuznetsov, V. N. \& Serpone, N. On the origin of the spectral bands in the visible absorption spectra of visible-light-active $\mathrm{TiO}_{2}$ specimens analysis and assignments. J. Phys. Chem. C 113, 15110-15123 (2009).

34. Li, M. et al. Photocatalytic hydrogen generation enhanced by band gap narrowing and improved charge carrier mobility in $\mathrm{AgTaO}_{3}$ by compensated co-doping. Phys. Chem. Chem. Phys. 15, 16220-16226 (2013).

35. Nozik, J. Photoelectrochemisty: applications to solar energy conversion. Annu. Rev. Phys. Chem. 29, 189-222 (1978).

36. Perdew, J. P., Burke, K. \& Ernzerhof, M. Generalized gradient approximation made simple. Phys. Rev. Lett. 77, 3865-3868 (1996); Phys. Rev. Lett. 78, 1396 (1997)(Erratum).

37. Cococcioni, M. \& Gironcoli, S. D. Linear response approach to the calculation of the effective interaction parameters in the LDA + U method. Phys. Rev. B 71, 035105 (2005). 
38. Baroni, S., Gironcoli, S., Corso, A. D. \& Giannozzi, P. Phonons and related crystal properties from density-functional perturbation theory. Rev. Mod. Phys. 73, 515-562 (2001).

39. Rettie, A. J. E. et al. Combined charge carrier transport and photoelectrochemical characterization of $\mathrm{BiVO}_{4}$ single crystals: intrinsic behavior of a complex metal oxide. J. Am. Chem. Soc. 135, 11389-11396 (2013).

40. Yin, W., Wei, S. -H., Al-Jassim, M. M, Turner, J. \& Yan, Y. Doping properties of monoclinic $\mathrm{BiVO}_{4}$ studied by first-principles density-functional theory. Phys. Rev. B 83, 155102 (2011).

41. Janotti, A., Varley, J. B., Choi, M. \& Van de Walle, C. G. Vacancies and small polarons in $\mathrm{SrTiO}_{3}$. Phys. Rev. B 90, 085202 (2014).

42. Austin, I. G. \& Mott, N. F. Polarons in crystalline and non-crystalline materials. Adv. Phys. 18, 41-102 (1969).

43. Ping, Y., Rocca, D. \& Galli, G. Electronic excitation in light absorbers for photoelectrochemical energy conversion: first principles calculations based on many body perturbation. Chem. Soc. Rev. 42, 2437-2469 (2013).

44. Ping, Y., Rocca, D. \& Galli, G. Optical properties of tungsten trioxide from first-principles calculations. Phys. Rev. B 87, 165203 (2013).

45. Fischer, D. \& Kersch, A. The effect of dopants on the dielectric constant of $\mathrm{HfO}_{2}$ and $\mathrm{ZrO}_{2}$ from first principles. Appl. Phys. Lett. 92, 012908 (2008).

46. Södergren, S., Hagfeldt, A., Olsson, J. \& Lindquist, S.-E. Theoretical models for the action spectrum and the current-voltage characteristics of microporous semiconductor films in photoelectrochemical cells. J. Phys. Chem. 98, 5552-5556 (1994).

47. Seabold, J. A., Zhu, K. \& Neale, N. R. Efficient solar photoelectrolysis by nanoporous $\mathrm{Mo}: \mathrm{BiVO}_{4}$ through controlled electron transport. Phys. Chem. Chem. Phys. 16, 1121-1131 (2014).

48. Abdi, F. F. \& Van de Krol, R. Nature and light dependence of bulk recombination in Co-Pi-catalyzed $\mathrm{BiVO}_{4}$ photoanodes. J. Phys. Chem. C 116, 9398-9404 (2012).

49. McDonald, K. \& Choi, K. -S. A new electrochemical synthesis route for a BiOI electrode and its conversion to a highly efficient porous $\mathrm{BiVO}_{4}$ photoanode for solar water oxidation. Energy Environ. Sci. 5, 8553-8557 (2012).

50. ASTM Standard G173-03, 2008. Standard Tables for Reference Solar Spectral Irradiances: Direct Normal and Hemispherical on $37^{\circ}$ Tilted Surface. ASTM International (West Conshohocken, PA, USA, 2003). doi: 10.1520/G0173-03R08, www.astm.org.

51. Dotan, H., Sivula, K., Grätzel, M., Rothschild, A. \& Warren, S.C. Probing the photoelectrochemical properties of hematite $\left(\alpha-\mathrm{Fe}_{2} \mathrm{O}_{3}\right)$ electrodes using hydrogen peroxide as a hole scavenger. Energy Environ. Sci. 4, 958-964 (2011).
52. Zhou, M. et al. Efficient water splitting via a heteroepitaxial $\mathrm{BiVO}_{4}$ photoelectrode decorated with Co-Pi catalysts. ChemSusChem. 5, 1420-1425 (2012).

53. Giannozzi, P. et al. QUANTUM ESPRESSO: a modular and open-source software project for quantum simulations of materials. J. Phys.: Condens. Matter 21, 395502 (2009).

54. Mott, N. F. Conduction in glasses containing transition metal ions. J. Non-Cryst. Solids 1, 1-17 (1968).

\section{Acknowledgements}

This work was supported by the National Science Foundation (NSF) under the NSF Center (CHE-1305124). Computer time was provided by NERSC. Y.P. and G.A.G. thank Dr. Hosung Seo for useful discussions.

\section{Author contributions}

K.-S.C. and G.A.G. supervised the project. T.W.K. planned and performed all experiments. T.W.K. and K.-S.C. interpreted the experimental results. Y.P. planned and performed all calculations. Y.P. and G.A.G. interpreted the calculations and consulted with K.-S.C. and T.W.K. to relate the calculation and experimental results. All authors contributed to writing the manuscript.

\section{Additional information}

Supplementary Information accompanies this paper at http://www.nature.com/ naturecommunications

Competing financial interests: The authors declare no competing financial interests.

Reprints and permission information is available online at http://npg.nature.com/ reprintsandpermissions/

How to cite this article: Kim, T. W. et al. Simultaneous enhancements in photon absorption and charge transport of bismuth vanadate photoanodes for solar water splitting. Nat. Commun. 6:8769 doi: 10.1038/ncomms9769 (2015).

(c) (i) This work is licensed under a Creative Commons Attribution 4.0 International License. The images or other third party material in this article are included in the article's Creative Commons license, unless indicated otherwise in the credit line; if the material is not included under the Creative Commons license, users will need to obtain permission from the license holder to reproduce the material. To view a copy of this license, visit http://creativecommons.org/licenses/by/4.0/ 